Research Article

\title{
Hardware-in-the-Loop Implementation and Performance Evaluation of Three-Phase Hybrid Shunt Active Power Filter for Power Quality Improvement
}

\author{
Ayesha Khan, ${ }^{1}$ Mujtaba Hussain Jaffery, ${ }^{2}$ Yaqoob Javed, ${ }^{2}$ Jehangir Arshad $\left(\mathbb{D},{ }^{2}\right.$ \\ Ateeq Ur Rehman $\left({ }^{3},{ }^{3}\right.$ Rabia Khan, ${ }^{4}$ Mohit Bajaj $₫{ }^{5}$, and Mohammed K. A. Kaabar $\mathbb{1}^{6,7,8}$ \\ ${ }^{1}$ Syed Babar Ali School of Science and Engineering, Lahore University of Management Sciences, Lahore 54000, Pakistan \\ ${ }^{2}$ Department of Electrical \& Computer Engineering, COMSATS University Islamabad, Lahore Campus, Lahore 54000, Pakistan \\ ${ }^{3}$ Department of Electrical Engineering, Government College University, Lahore 54000, Pakistan \\ ${ }^{4}$ School of Electrical Engineering and Computer Science, Washington State University, Pullman, WA 97124, USA \\ ${ }^{5}$ Department of Electrical and Electronic Engineering, National Institute of Technology Delhi, New Delhi 110040, India \\ ${ }^{6}$ Gofa Camp, Near Gofa Industrial College and German Adebabay, Nifas Silk-Lafto, 26649 Addis Ababa, Ethiopia \\ ${ }^{7}$ Jabalia Camp, United Nations Relief and Works Agency (UNRWA) Palestinian Refugee Camp, Gaza Strip Jabalya, \\ State of Palestine \\ ${ }^{8}$ Institute of Mathematical Sciences, Faculty of Science, University of Malaya, Kuala Lumpur 50603, Malaysia
}

Correspondence should be addressed to Mohammed K. A. Kaabar; mohammed.kaabar@wsu.edu

Received 12 May 2021; Accepted 15 September 2021; Published 14 October 2021

Academic Editor: Min Ye

Copyright ( 92021 Ayesha Khan et al. This is an open access article distributed under the Creative Commons Attribution License, which permits unrestricted use, distribution, and reproduction in any medium, provided the original work is properly cited.

\begin{abstract}
The excessive use of nonlinear load causes electric current harmonics that ultimately downgrades the electrical power quality. If a failure exists due to internal integration of a power system in any one of the internal networks, it causes uncomplimentary consequences to the entire power system's performance. This paper proposed a hybrid shunt active harmonic power filter (HSAHPF) design to reduce harmonic pollution. A digital controller HIL simulator has been modeled using a three-phase voltage source inverter to test the efficiency of HSAHPF and the performance of control algorithms. Moreover, the instantaneous active and reactive current theory $\left(I_{d}-I_{q}\right)$ and instantaneous active and reactive power theory $(\mathrm{Pq} 0)$ control algorithms are implemented for the reference current generation in HSAHPF, resulting in reduced harmonic distortions, power factor improvement for a balanced nonlinear load. The control algorithms are further employed in Arduino MEGA to keep the factor of cost-effectiveness. The simulation of the proposed design has been developed in Simulink. The validation and testing of HSAHPF using controller HIL simulation prove the control algorithms' ability to run in a portable embedded device. The statistical analysis of the proposed system response provides a minimum total harmonic distortion (THD) of 2.38 from 31.74 that lies in IEEE 519-1992 harmonic standards with an improved stability time of $0.04 \mathrm{~s}$. The experimental verification and provided results of the HIL approach validate the proposed design. Significant mitigation of harmonics can be observed, consequently enhancing the power quality with power factor near unity.
\end{abstract}

\section{Introduction and Related Studies}

The delivery of quality power through power systems is a global business, and it has remained a focal point for industry professionals and researchers during the last few decades. The use of nonlinear load in industries increases harmonic pollution and downgrades the electric power quality. The network failure occurs due to the power system's internal integration that causes uncomplimentary consequences to the entire system. In recent years, electric current harmonics and their mitigation are hot topics in industries. The excessive nonlinear load reduces the equipment life and degrades the electric power quality. In Pakistan, industries are using power factor (pf) improvement devices to improve power quality. For attaining this purpose, capacitors are used instead of reactors, which introduce odd harmonics and 
resonance into the power system. In addition, the nonlinear loads draw current, which is not flawlessly sinusoidal as the current waveform diverges from a sine wave; hence, the distortions in voltage waveforms are created. The harmonics are responsible for electronics miss-timings, increased heating effect in electrical equipment, overheating power transformers, capacitor overloads, and losses in distribution lines $[1,2]$.

There are numerous filtering techniques for harmonics mitigation proposed in the existing literature, that is, passive power filter (PPF), active power filter (APF), and hybrid power filter (HPF). The PPF technique has been used to provide a low-impedance path to harmonics of different frequencies and diminishes their effect using tuned capacitors, reactors, and resistors. These are low cost, but the major disadvantage of using the PPF is producing resonance in the power system [3]. Moreover, APF is used where the voltage sag and swell with spikes are present. Their major drawback is a high operating cost and limitation for low rating load in industries $[4,5]$. A combination of PPF and APF into a single device (known as a hybrid filter) is used where both current and voltage harmonics show degeneration in the power system's performance. They are further divided into two types: shunt hybrid and series hybrid filters. Total load current passes through series hybrid filter, enhancing the power losses as they are directly proportional to the current $\left(P=I^{2} R\right)$. The shunt hybrid filters are preferred due to their durability, performance consistency, and low power losses [6]. For the deployment of APF and HPF, several control strategies, such as selective harmonic elimination-based pulse width modulation (SHE-PWM), fast Fourier transformation technique (FFT), recursive discrete Fourier transformation (RDFT), Pq0, direct testing and calculating (DTC) methods, that is, $I_{d}-I_{q}[7,8]$, notch filter, generalized integral, sine wave multiplication, adaptive filter, synchronous detection algorithm, artificial neural network (ANN), adaptive linear neuron (ADALINE), wavelet transformation (WT), particle swarm optimization (PSO), and genetic algorithm (GA) techniques have been presented in the literature $[9,10]$. Developing a practical and real-time system has a significant task. An appropriate control algorithm is implemented using the digital signal processor for the applied control engineering (dSPACE) board as an archetype, based on the DS1104 microcontroller. Various techniques were used to develop real-time simulation platforms for the designing, analyzing, and testing power systems, and their practical applications were discussed. The major components of a real-time digital system (RTDS) used in engineering industries and academia were deliberated for summarizing its significant features for a better understanding of relevant techniques $[11,12]$.

A shunt hybrid compensator centered on the synchronous rotating reference frame (SRRF) control algorithm in the direct quadrature $(\mathrm{Dq})$ axis is designed and fabricated in HIL to improve the steady-state power factor and at the supply side to ensure the dynamic harmonic compensation. Performance analysis is done through MATLAB simulations for varying loads, while THD at the supply side and current harmonics reduction were also confirmed [13]. Moreover, a photovoltaic (PV)-incorporated SAPF has been designed and implemented in MATLAB/Simulink to improve the power quality to generate clean electrical power. Various control techniques, such as ANN, fuzzy logic control technique (FLC), an adaptive neuro-fuzzy-based inference system (ANFIS)-based controller maximum power point tracking (MPPT) to extract maximum power from PV-integrated SAPF, with SRRF-based control algorithm for reference current extraction are executed and validated with strong computational engine OPAL-RT 4510 based on field programmable gate array (FPGA) for real-time testing. The performance evaluation and comparison of various control algorithms (for balanced and unbalanced load) based on THD, losses, voltage drop, and pf have been presented along with optimized cost analysis by Kumar and Bansal [14] and Asif et al. [15].

Furthermore, SAPF is implemented using adaptive frequency-based reference compensation current as control topology and is verified with HIL by Chen et al. [16]. In addition, to investigate the experimental efficiency of HILbased power electronics devices and applications, a singlephase transformer-less hybrid series active filter (THSeAF) has been implemented based on a duo-neutral point clammed (D-NPC) converter for discussing the power quality at the distribution level. The HIL benchmark presented a five-level D-NPC-THSeAF in Javadi et al.'s study [17] using the OPAL-RT simulator for the electrical system. Moreover, the controller has been implemented on dSPACE as an interface. This work also presents real-time testing and is validated using the HIL technique [17]. The particle swarm grey wolf optimization (PSO-GWO) and fractional-order proportion-integral-derivative (FOPID) control techniques have been implemented for power quality enhancement, and the parameters of the FOPID controller are tuned by the PSO-GWO algorithm [18].

To connect a run-time simulator with a hands-on embedded controller, it receives an analog signal from the RTBox simulator that executes it to generate gate signals to send back to the simulator for proper switching. Both are interconnected with launch-pad interfacing [19]. A real-time simulator introduced by RTDS technologies has been employed to perform a two-level simulation (three-phase VSI with parallel connection of a single tuned passive filter). Moreover, it has been implemented and tested in HIL while the control algorithm has been executed in the hardware [20]. Dq current control technique for generating reference current using a modified phase-locked loop (PLL) approach is simulated in Simulink, to handle the double frequency components of nonsinusoidal voltages. The proportionalintegral (PI) controller has been used in the DC-voltage loop. A testbed prototype for verification of SHAPF is also built on the dSPACE1104 controller for real-time execution [21].

SHAPF is designed and simulated in Simulink for multiple harmonics mitigation using an innovative controller. The verification of the electronic control strategy of SHAPF was experimentally done on a digital signal processor (DSP)-based microcontroller unit [22]. Pq0 theory is implemented to extract reference currents and all the three 
phases for balanced and unbalanced nonlinear load, and to obtain the switching angles and gate pulses for controlling the VSI switches, hysteresis current controller is employed in MATLAB/Simulink. The target of these studies is to design and implement a power filter that can minimize the harmonics within the specified range of IEEE standards [23]. Multiple fuzzy membership functions, that is, triangular, Gaussian, and trapezoidal, are used with SAPF for improved power quality and eradicating uncertainties from the system using $\left(I_{d}-I_{q}\right.$ and $\left.\mathrm{Pq} 0\right)$ control strategy. The real-time testing of results has been validated through hardware implementation on OPAL-RT. Comparing different membership functions with FLC using the same control strategy is also done [24]. The latest method for restraining unwanted distortions for determining the STPF compensator value in a non-sinusoidal power system using nonlinearity current index (NLCI) has been suggested and implemented in the proposed paper [25].

The existing literature presents various APF design and control techniques for harmonics mitigation, reactive power compensation, and power quality improvement. The majority of previous efforts aimed to verify the power quality using run-time simulators for balanced three-phase systems. However, to the best of our knowledge, the proposed methodology for HSAHPF development through embedded system and simulation interface (Simulink) is a novel implementation. Moreover, the proposed system also demonstrates the ability of control algorithms to run in a portable embedded device. Furthermore, this work aims to develop an HIL simulator framework for monitoring and verifying three-phase HSAHPF to detect harmonics in the system and mitigate their effect on power quality improvement. The main objectives of the proposed technique are listed as follows:

(i) Development of controller HIL simulations that facilitate the integration of embedded system (Arduino) into the simulation interface (Simulink).

(ii) Implementation of control algorithms based on $\mathrm{Pq} 0$ and $I_{d}-I_{q}$ with hysteresis control topology (in outer loop) and PI controller (in inner loop) using controller HIL testing method.

(iii) Comparative analysis of both techniques in the HIL controller.

A controller HIL technique has been implemented by interfacing Simulink with an external controller board (Arduino) and transforming $\mathrm{Pq} 0$ and $I_{d}-I_{q}$ control techniques into programmed control codes for HSAHPF to generate the reference currents for harmonics mitigation. Controller HIL is a productive platform in academics and practical conditions to minimize the cost, risk, and duration. The key benefit of HIL controller's implementation is that the complete system (including power and control circuits) can be verified without accurate power transfer. Thus, it becomes a secure and reliable testing approach for power systems. The block diagram of the overall proposed technique is depicted in Figure 1.
The block diagram of SHAHPF in Figure 1 illustrates that $V_{s a}, V_{s b}$, and $V_{s c}$ are the voltages across all the phases, $I_{l a}$, $I_{l b}$, and $I_{l c}$ are the load currents across three phases, $I_{c a}, I_{c b}$, and $I_{c c}$ are the filter currents, and $V_{\mathrm{dc}}$ is the capacitor voltage. To reduce the power rating for conventional 3 legs and 6 IGBTs of APF, a single tuned passive harmonic power filter tuned for fifth-order harmonics was implemented in Simulink. At the same time, the targeted part for HIL is the control strategy implemented in APF. The primary purpose of HIL testing is to generate the C language code for reference currents according to the aforementioned control algorithms that are equal in magnitude but opposite with $180^{\circ}$ phase-shifted current signals. It is used to overcome the effect of distorted harmonic waveform which is implemented in microcontroller. Moreover, a detailed comparative analysis of Simulink and HIL controller-based techniques on THD and efficiency is performed.

The rest of the sections in this paper are organized as follows: Section 2 presents the power circuit topology of HSAHPF and the fundamentals of HIL implementation, conventional control techniques for hybrid filters, design parameters for power circuits, and proposed control algorithms along with their implemented model in Simulink and HIL controller. In Section 3, controller HIL simulations and results are presented that contribute to the discussion of theoretical and experimental results verified through HIL simulations. In Section 4, a comparative analysis of both proposed and conventional techniques is discussed based on THD and HIL-implemented control algorithms' effectiveness. Finally, Section 5 encapsulates the findings and substantial contributions of this research work.

\section{Materials and Methods}

We have proposed a design of HSAHPF filter to minimize the harmonics from electric current and hence, enhance the electric power quality. A digital controller HIL simulationbased technique is implemented for power quality improvement and THD reduction. Moreover, different controlled methods are implemented along with Arduino MEGA to keep the factor of cost-effectiveness. The following subsections provide the details of implementation.

2.1. Power Circuit Configuration of HSAHPF. The power circuit of HSAHPF is designed in Simulink combined with a single tuned PPF in series with APF (Figure 2). The PPF in HSAHPF contains a single tuned RL circuit used for loworder load current harmonics compensation, that is, third and fifth order. It also compensates reactive power components due to highly nonlinear load. For low-voltage distribution systems and grounded transmissions, the neutral wire current is commonly used. The source current $\left(I_{s a b c}\right)$ is mainly comprised of the load current $\left(I_{\text {Loabc }}\right)$ and the compensating current $\left(I_{c a b c}\right)$ to avoid the harmonics distortion of PPF.

Furthermore, APF mainly consists of a DC-link capacitor bank and a VSI. The central part of HSAHPF is VSI that produces the reference current in coordination with a 


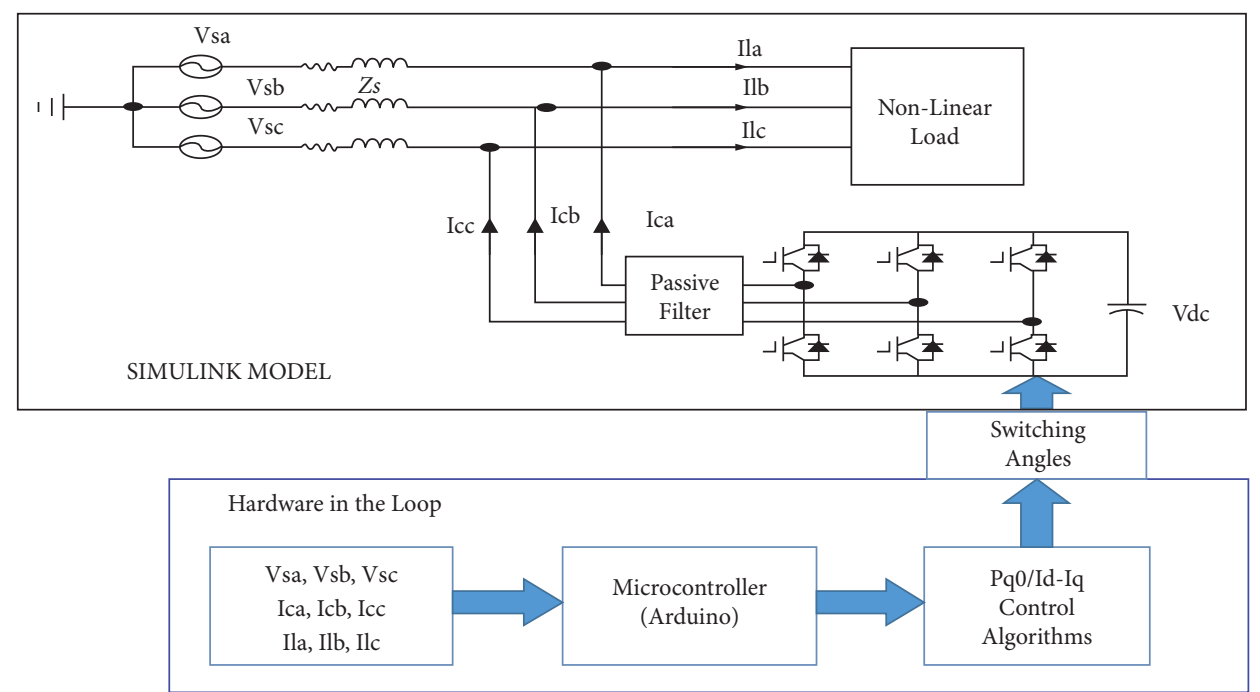

FIGURE 1: Block diagram of HIL control-based hybrid shunt active harmonic power filter.

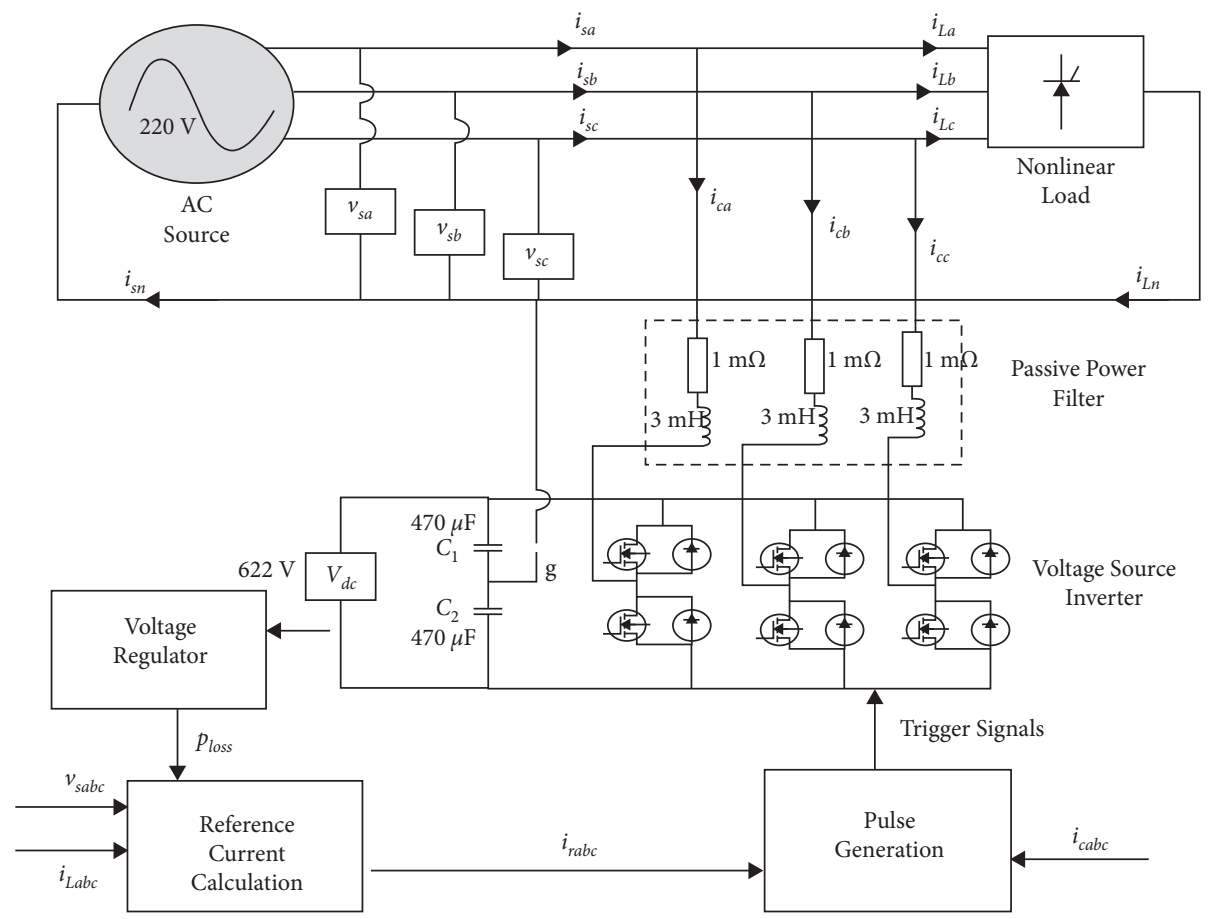

FIGURE 2: Hybrid shunt active harmonic power filter with nonlinear load for current compensation.

voltage regulator to compensate harmonics. Hence, the switching losses are reduced effectively using the proposed configuration of HSAHPF. The voltage rating of APF is also minimized due to its low DC reference voltage constraint through the avoidance of both series and parallel resonance. In this paper, HSAHPF has been implemented with two different models and control techniques in Simulink. The power circuit remains modeled inside the Simulink with the control algorithms employed in microcontroller for monitoring and verification.
2.2. Conventional Control Methods. The performance of the HSAHPF is like an open circuit for the harmonics introduced by the switching devices. An assumption has been made that any set of arbitrarily chosen reference currents can be drawn by the compensator behaving like a controlled current source to introduce a simple design of the HSAHPF. The basic idea for the harmonic current compensation using a parallel-connected filter is illustrated in Figure 3. The PPF is tuned for a specific harmonic frequency based on reactive power compensation. The prominent harmonic in the 
system is under observation as the source current, including the load current and the compensating current to evade the harmonic propagation raised by the resonance of the PPF. The continuous harmonic damping can also be provided throughout the power line using an HSAHPF. The energy storage element that is a capacitor for VSI must be large enough that should not allow the system to experience significant voltage variations. The converter will surely lose its controllability if the DC voltage gets lower in magnitude than $\mathrm{AC}$ voltage.

\subsubsection{Instantaneous Active and Reactive Power Theory (Pq0).} Time-domain defines the set of instantaneous powers on that the Pq0 theory is based. It is equally valid in both transient and steady states because it can be applied to the $3-\varnothing$ and three-wire or four-wire system without any modifications or restrictions. The aforementioned theory is very systemized and versatile regarding the controller design for the power electronics-based power filters. The two significant transformations involved in this theory are as follows: (1) the transformation of power system current and voltage from $a b c$ domain to $\alpha \beta 0$ domain and (2) the transformation of $\alpha \beta 0$ domain voltage and current into active and reactive powers.

(1) Clarke transformation includes the conversion of three-phase instantaneous currents and voltages from $a b c$ phases to $\alpha \beta 0$ coordinates. Clarke transformation for both current and voltages for power invariance case are under observation in equations (1) and (2) [26]:

$$
\begin{aligned}
& {\left[\begin{array}{l}
i_{\alpha} \\
i_{\beta} \\
i_{0}
\end{array}\right]=\frac{\sqrt{ } 2}{\sqrt{ } 3}\left[\begin{array}{ccc}
1 & \frac{-1}{2} & \frac{-1}{2} \\
0 & \frac{\sqrt{3}}{2} & \frac{-\sqrt{3}}{2} \\
\frac{1}{\sqrt{ } 2} & \frac{1}{\sqrt{ } 2} & \frac{1}{\sqrt{ } 2}
\end{array}\right]\left[\begin{array}{l}
i_{a} \\
i_{b} \\
i_{c}
\end{array}\right],} \\
& {\left[\begin{array}{l}
v_{\alpha} \\
v_{\beta} \\
v_{0}
\end{array}\right]=\frac{\sqrt{2}}{\sqrt{ } 3}\left[\begin{array}{ccc}
1 & \frac{-1}{2} & \frac{-1}{2} \\
0 & \frac{\sqrt{3}}{2} & \frac{-\sqrt{3}}{2} \\
\frac{1}{\sqrt{ } 2} & \frac{1}{\sqrt{ } 2} & \frac{1}{\sqrt{ } 2}
\end{array}\right]\left[\begin{array}{l}
v_{a} \\
v_{b} \\
v_{c}
\end{array}\right] .}
\end{aligned}
$$

(2) Similarly, inverse Clarke transformation for both current and voltages can be observed in equations (3) and (4) and can be verified from details explained by Balasubramanian et al. and Jawad and Iqbal [13, 27].

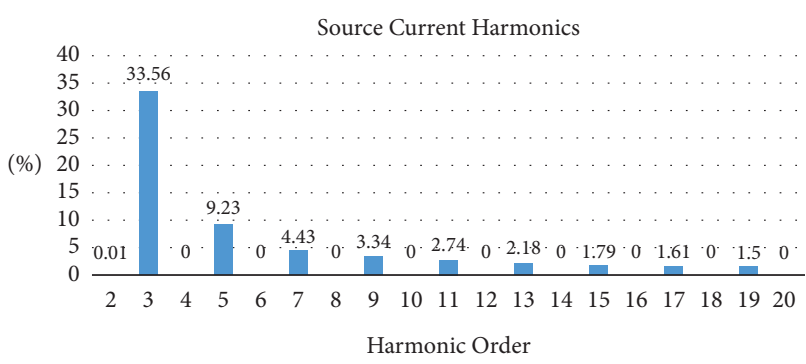

FIGURE 3: Source current harmonics without any filter.

$$
\begin{aligned}
& {\left[\begin{array}{l}
i_{a} \\
i_{b} \\
i_{c}
\end{array}\right]=\frac{\sqrt{2}}{\sqrt{3}}\left[\begin{array}{ccc}
1 & 0 & \frac{1}{\sqrt{2}} \\
\frac{-1}{2} & \frac{\sqrt{3}}{2} & \frac{1}{\sqrt{2}} \\
\frac{1}{2} & \frac{-\sqrt{3}}{2} & \frac{1}{\sqrt{2}}
\end{array}\right]\left[\begin{array}{l}
i_{\alpha} \\
i_{\beta} \\
i_{0}
\end{array}\right],} \\
& {\left[\begin{array}{l}
v_{a} \\
v_{b} \\
v_{c}
\end{array}\right]=\frac{\sqrt{2}}{\sqrt{3}}\left[\begin{array}{ccc}
\frac{-1}{2} & \frac{\sqrt{3}}{2} & \frac{1}{\sqrt{2}} \\
\frac{1}{2} & \frac{-\sqrt{3}}{2} & \frac{1}{\sqrt{2}}
\end{array}\right]\left[\begin{array}{l}
v_{\alpha} \\
v_{\beta} \\
v_{0}
\end{array}\right] .}
\end{aligned}
$$

Clarke and its inverse transformation both have the attribute of invariance of power. In a three-phase system, this characteristic is preferred when the primary target is the inspection of instantaneous power. Applying the transformation of instantaneous voltage and current from $3-\varnothing a b c$ to $\alpha \beta 0$ axes, the real power $(p)$, imaginary power $(q)$, and zero sequence power $\left(p_{0}\right)$ are defined in equation (5), which is also mentioned by Kumar and Mikkili [24].

$$
\left[\begin{array}{c}
p \\
q \\
p_{0}
\end{array}\right]=\left[\begin{array}{ccc}
0 & v_{\alpha} & v_{\beta} \\
0 & v_{\beta} & -v_{\alpha} \\
v_{0} & 0 & 0
\end{array}\right]\left[\begin{array}{c}
i_{0} \\
i_{\alpha} \\
i_{\beta}
\end{array}\right] .
$$

The inverse of the earlier transformation will be observed in equation (6).

$$
\left[\begin{array}{c}
i_{o} \\
i_{\alpha} \\
i_{\beta}
\end{array}\right]=\frac{1}{v_{0} A}\left[\begin{array}{ccc}
v_{0} v_{\alpha} & v_{0} v_{\beta} & 0 \\
v_{0} v_{\beta} & -v_{0} v_{\alpha} & 0 \\
0 & 0 & A
\end{array}\right]\left[\begin{array}{l}
p \\
q \\
p_{0}
\end{array}\right],
$$

where 


$$
A=v_{\alpha}^{2}+v_{\beta}^{2}
$$

(3) Applications of Clarke transformation: Clarke transformation assumes symmetry in a three-phase circuit, so Clarke's simple application does not produce matrices' diagonalization. In Bellan's study [28], a time-domain analysis due to line switching in a three-phase system is presented based on mathematical modeling. Clarke transformation is applied across each triplet of phase voltages and currents that deal with the asymmetry in three-phase systems. A few of its applications are as follows:

(i) They are used in brilliant for maximum likelihood frequency estimation.

(ii) They are used for wide frequency range applications.

(iii) They are used for estimating the frequency of threephase balanced and unbalanced power systems.

(iv) They are used for three-phase adaptive frequency measurement.

(v) They are used for transient analysis of three-phase single line-to-ground faults.

The $\mathrm{Pq} 0$ theory does not contradict the frequency domain conventional theory, but it is complement in the time domain. Its ability to thoroughly analyze a three-phase system and run-time calculations of all the powers and currents is an attractive topology. All the undesirable currents can be discovered and removed simultaneously, improving system efficiency [26]. In a power system suffering the presence of current harmonics, all the currents with undesirable frequencies in the system can be eliminated by introducing the currents with the same amplitude but $180^{\circ}$ phase-shifted of the undesirable current waveforms, making the system current sinusoidal.

2.2.2. Instantaneous Active and Reactive Current Theory $\left(I_{d}-I_{q}\right)$. Filter currents are obtained from the nonlinear load's instantaneous active and reactive current components $I_{l d}$ and $I_{l q}$, which are then fed to a vector rotation block that is rotated over an angle $\theta$ to match the frame $I_{l d}$ and $I_{l q}$, using the Park transformation. The quantities described in $I_{d}-I_{q}$ coordinates are fixed (constant) for a constant amplitude signal. $I_{d}-I_{q}$ gives the advantage to design controllers for low-frequency tracking (since the quantities are described as DC quantities in this frame):

$$
\left[\begin{array}{l}
i_{d} \\
i_{q}
\end{array}\right]=\left[\begin{array}{cc}
\cos \theta & \sin \theta \\
-\sin \theta & \cos \theta
\end{array}\right]\left[\begin{array}{l}
i_{l \alpha} \\
i_{l \beta}
\end{array}\right],
$$

where $\theta=\tan ^{-1}\left(v_{\beta} / v_{\alpha}\right)$,

$$
\left[\begin{array}{l}
i_{d} \\
i_{q}
\end{array}\right]=\frac{1}{\sqrt{\left(v_{\alpha}^{2}+v_{\beta}^{2}\right)}}\left[\begin{array}{cc}
v_{\alpha} & v_{\beta} \\
-v_{\beta} & v_{\alpha}
\end{array}\right]\left[\begin{array}{l}
i_{\alpha} \\
i_{\beta}
\end{array}\right] .
$$

Each current component $\left(I_{d}-I_{q}\right)$ has an average value or DC component and an oscillating value or AC component because $I_{d}-I_{q}$ theory gives the advantage to design a controller for low-frequency tracking. The control technique's mathematical modeling is attached in Appendix B and verified by Kumar and Mikkili [24].

$$
\begin{gathered}
i_{l d}=i_{\overline{l d}}+i_{\tilde{l d}}, \\
i_{l q}=i_{\overline{l q}}+i_{l_{q}} .
\end{gathered}
$$

The first-order harmonic current of the positive sequence that comprises an average current component can be changed to DC quantities. All higher-order harmonic currents with the first harmonic of the negative array of current will be shifted to non-DC quantities, inducing a frequency shift in the spectrum constituting oscillatory components. The average currents are mitigated by Butterworth filter, and the currents that will be compensated are $i_{c d}=i_{\tilde{l d}}$ and $i_{c q}=i_{\overrightarrow{l q}}$. So, the compensation currents can be calculated using equations (11) and (12):

$$
\left[\begin{array}{c}
i_{c \alpha} \\
i_{c \beta}
\end{array}\right]=\frac{1}{A}\left[\begin{array}{cc}
v_{\alpha} & -v_{\beta} \\
v_{\beta} & v_{\alpha}
\end{array}\right]\left[\begin{array}{l}
i_{c d} \\
i_{c q}
\end{array}\right],
$$

where

$$
A=\sqrt{\left(v_{\alpha}^{2}+v_{\beta}^{2}\right)}
$$

The leading advantage of implementing this technique is that the PLL is no more compulsory to find phase angle $\theta$, as it can be directly calculated from the fundamental voltages; therefore, it also makes this frequency-independent by avoiding the PLL [29].

\subsection{Designed Parameters and Proposed Control Techniques.}

The effectiveness of the proposed HSAHPF using various control algorithms to mitigate current harmonics due to the presence of nonlinear loads has been assessed through simulation software using MATLAB/Simulink. A $10 \mathrm{kVA}$, $220 \mathrm{~V}$, HSAHPF has been implemented at $50 \mathrm{~Hz}$ fundamental frequency to improve power quality. With the boom of embedded systems and the enlargement of microcontrollers, Arduino becomes a significant way to substantiate the control algorithms to test three-phase HSAHPF. The description, specifications, and parameters of the system under study are given in Table 1 . These parameters are taken from Jawad and Iqbal's study [27], and the designed steps are also mentioned in Appendix A that helped us to decide the order of filter.

Table 1 presents the amount of the first 20 harmonics for $I_{s a b c}$. For HSAHPF, to reduce the power rating of the APF, losses, and cost, the fifth-order harmonic is eradicated through PPF technique. All the remaining harmonics are diminished by the APF except the third. The load current flow can be restricted into PPF, and it functions as a harmonic isolator in the device between the source and loads. Figure 3 represents the source current harmonics without implementing the filter.

Overall, 33.84\% THD for $I_{s a b c}$ is observed from Figure 3. It is outside the range set by international standards to achieve IEEE 519-1992 for current harmonics. Moreover, the $V_{s a b c}$ has a THD of $0.017 \%$ that already exists within the optimal harmonics range; thus, no further enhancement has 
TABLE 1: Parameters for testing the load situation with designed HSAHPF [27].

\begin{tabular}{lc}
\hline System parameters & Physical values \\
\hline Power rating & $10 \mathrm{kVA}$ \\
Phase voltage RMS value & $220 \mathrm{~V}$ \\
Frequency & $50 \mathrm{~Hz}$ \\
$C_{1}=C_{2}$ & $470 \mu \mathrm{F}$ \\
$L_{f}$ & $3 \mathrm{mH}$ \\
$R_{f}$ & $1 \mathrm{~m} \Omega$ \\
$V_{\text {ref }}$ & $622 \mathrm{~V}$ dc \\
$k_{i}$ & 17 \\
$k_{p}$ & 25 \\
Single-phase rectifier nonlinear load $(R, L$, and $C)$ & $43.2 \Omega, 34.5 \mathrm{mH}$, and $392 \mu \mathrm{F},(720 \mathrm{VAR})$ \\
\hline
\end{tabular}

been required in $V_{s a b c}$; however, there is an imperative need to improve the $I_{s a b c}$ as the THD should lie within the standard range.

Figure 4 represents the source current harmonics waveform in a three-phase system without implementing HSAHPF. It can be observed from Figure 4 that due to the presence of nonlinear load, the source current is not sinusoidal, and it also contains spikes due to capacitor charging (attached with the VSI).

Figure 5 depicts the source voltages using a three-phase system without the implementation of HSAHPF. As the attached nonlinear load across all the three phases is balanced, the obtained source voltages are sinusoidal. It can be observed that the source voltages do not contain any harmonics; hence, they are not contributing any significant role in polluting the power system. The primary goal is to remove the source current harmonics and lower the THD. Simulink is a MATLAB-based graphical programming environment for system modeling, simulation, evaluation, and analyzing multidomain dynamical systems. It has been used to design and simulate the plant/ system before implementing the hardware model. The conversion blocks have been removed, and serial communication has been established to build the HIL because serial communication is the most reliable mode of communication. The Arduino environment's built-in serial monitor is used to communicate with an Arduino board attached to the computer via USB and interface cable to enable serial communication through the software's serial monitor window (IDE). The button selects the same baud rate used in the call to begin () their synchronization. Once the Simulink is set up for serial communication, the Arduino is set up to establish serial communication. The number of variables being sent by the Simulink is initialized.

Similarly, the variables that are required to be sent back are initialized. The data are transmitted in the form of unit 8 bytes. Other operations, such as PID control and filters, are also implemented using user-defined functions and Arduino libraries. The flow for the control theories was followed as they were implemented in the original Simulink files after uploading the code to Arduino. The setup was run and calibrated, and sampling time was adjusted accordingly. Technique. Initially, Pq0-based HSAHPF was implemented

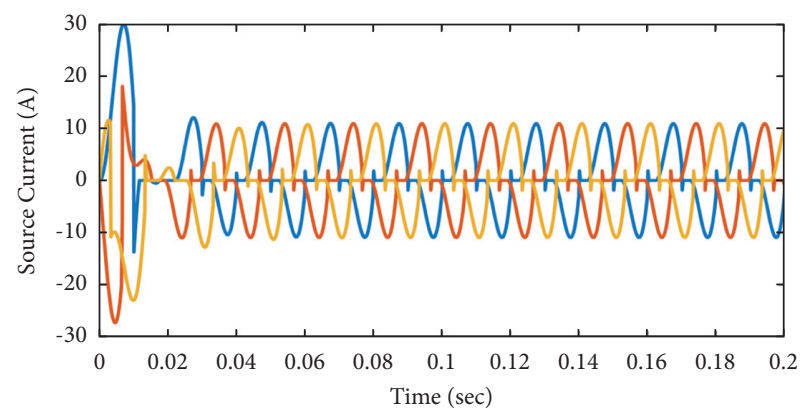

Figure 4: Source current harmonics without filter.

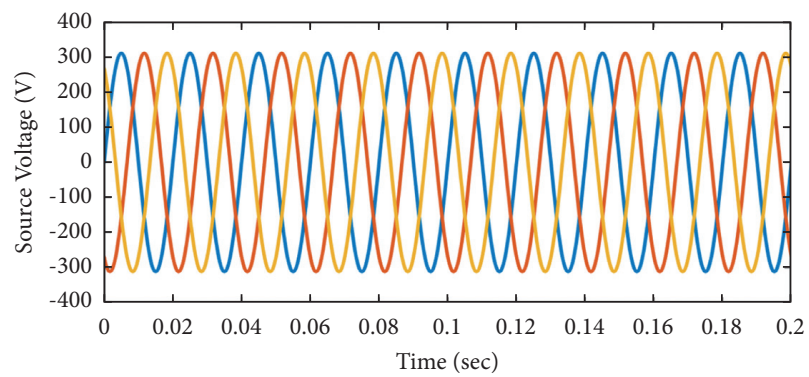

FIGURE 5: Source voltage harmonics without filter.

in Simulink using a three-phase, four-wire that contains four functional blocks.

(i) The 'DC' voltage regulator.

(ii) Calculation of instantaneous powers.

(iii) Selection of power for compensation.

(iv) Calculation of reference currents.

The excessive part of real power $\left(p_{\text {loss }}\right)$ is regulated by the DC voltage regulator to maintain the voltage of the capacitor $\left(V_{\mathrm{dc}}\right)$ close to the reference DC-link voltage $\left(V_{\mathrm{ref}}\right)$. The DC capacitors $\left(C_{1}\right.$ and $\left.C_{2}\right)$ shown in Figure 2 plays a significant role in the $\mathrm{Pq} 0$ control technique, will go on discharging only, instead of charging if $p_{\text {loss }}$ is not drawn continuously from the power circuit in this PWM control-based converter to supply the losses caused by switching operation. The second block contains the selection of power of the nonlinear load to be compensated with a low-pass filter and the influence of the DC-voltage regulator. This control block 
takes $V_{s a b c}\left(v_{s a}, v_{s b}, v_{s c}\right)$ and $I_{L a b c}\left(i_{L a}, i_{L b}, i_{L c}\right)$ as inputs. The zero sequence active power $\left(p_{0}\right)$, reactive power $(q)$, and active power $(p)$ is calculated after the application of transformations on the $V_{s a b c}$ and $I_{L a b c}$ as illustrated in Figure $6, p_{\text {loss }}$ is subtracted from the real power output $\widetilde{p}$ of the low-pass filter fed to the inverse Pq0 block and the compensating reactive power $(q)$ to give the final output. The fourth-order low-pass filter is more suitable for the separation of active power into average $(\bar{p})$ and oscillating parts $(\widetilde{p})$.

The third block calculates the reference currents using the instantaneous compensating powers, $i_{0}$ and the phase voltages as inputs. The power circuit for the active filter part consists of a center split VSI that consists of 6 MOSFETs with freewheeling diodes. The MOSFETs are used for switching purposes as they can operate at the high switching frequency, fast switching response, and low-voltage drop across them. The performance of this VSI with a combination of hysteresis controller and PWM behaves like a controlled current source.

The Simulink model shown in Figure 7 implements $\mathrm{Pq} 0$ theory as a control technique using three-phase, four-wire HSAHPF according to the earlier explanation. The system response using $\mathrm{Pq0}$ control technique and results will be explained later in Section 3.

2.3.2. Hardware-in-the-Loop-Based Pq0 Implementation. High-power and high-voltage systems are demanding, difficult, expensive, and dangerous to evaluate the controller for its testing. The invention of digital simulations and laboratory equipment helps design and test such complex systems, but this was not far enough because they cannot keep up with the pace of real-time processes. Due to the computational burden, the system's calculations were not fast enough to provide output requiring signals at fixed intervals. The calculation time needed for the system is much greater than the necessary time, so these high-speed calculations can be attained using HIL simulations. The integration of the actual hardware controller with the simulation network gives multiple advantages for the designed system's run-time testing. Power HIL is an indirect approach representing realtime, real-world operations and applications to certify the stable and accurate closed-loop simulations; however, it is an expensive and complex approach that involves real power transfer [30]. That is why, controller HIL is implemented in the proposed work, and to set up the HIL, the conversion blocks were removed, and serial communication was established. The overall setup is depicted in Figure 8, representing run-time monitoring and implementation of the proposed system.

2.3.3. Simulink-Based Implementation of $I_{d}-I_{q}$ Control Technique. The entire method of reference current generation using $I_{d}-I_{q}$ control topology is explained in Figure 9. It includes HSAHPF implemented in Simulink using a threephase, three-wire system that contains three functional blocks. (i) The DC voltage regulator using a PI controller.

(ii) The calculation of instantaneous current components using Clarke and Park transformation.

(iii) Calculation of reference currents using a hysteresis controller.

The hysteresis current controller was developed to generate the switching pulses to control VSI switches by comparing the real current to the reference current. The control scheme gives the switching pattern of active filter switches to maintain the real injected current within a desired hysteresis band. Thus, the considered hysteresis band in this work is $-(1 / 2) V_{\mathrm{DC}}$ to $(1 / 2) V_{\mathrm{DC}}(-313$ to 313$)$. The switching frequency of hysteresis current control (HCC) strategy depends mainly on how efficiently the current changes from upper limit to lower limit of hysteresis band and vice versa. Thus, the switching frequency varies with the obtained current waveform rather than a constant value throughout the switching operation of MOSFETS.

The park transformation is used to eliminate the DC components in nonlinear $I_{d}$, and $I_{q}$ load currents passed through an eighth-order Butterworth filter instead of the high-pass filters implemented in previous works. It provides an advantage in the minimization of fluctuations, and filters give the ideal response. The eighth-order Butterworth filter used in the harmonics installation circuit has a cut-off frequency of nearly $1 \mathrm{rad} / \mathrm{sec}$, due to which a high transient response and a slight phase shift in harmonics can be attained. A PI controller is used to keep the capacitor's voltage $\left(V_{\mathrm{dc}}\right)$ relative to a DC-link reference voltage $\left(V_{\mathrm{ref}}\right)$. This approach's benefit is that angle " $\theta$ " can be measured directly from the primary voltages. Moreover, an excessive amount of synchronization problems can be avoided in the presence of unbalanced and nonsinusoidal mains voltage conditions. The implemented Simulink model is shown in Figure 10.

\subsubsection{Hardware-in-the-Loop-Based $I_{d}-I_{q}$ Implementation.} For creating the hardware-in-the-loop structure, the Simulink is set up for serial communication. The Arduino MEGA is used to establish serial communication. Although serial communication is reliable to a great extent, it is limited by several factors. One of the main factors is the sampling time. The sampling time is one of the key elements that govern the speed of the simulation. Since the maximum data rate for Arduino is limited to 115,200 , the simulation cannot progress at a very high pace; therefore, the full simulation speed is limited to a multiple of the time required to send data, compute it, and receive the data back.

In this technique, all the functional blocks, that is, DClink voltage regulator, control algorithm of $I_{d}-I_{q}$ are implemented in Arduino. At the same time, hysteresis controller remains implemented in Simulink for obtaining more efficient results. Initially, the primary voltages and current measurements are sent as input to the serial send. To send multiple values, an MUX is used, then a zero-order hold to add some hold on between the values. Then the data 


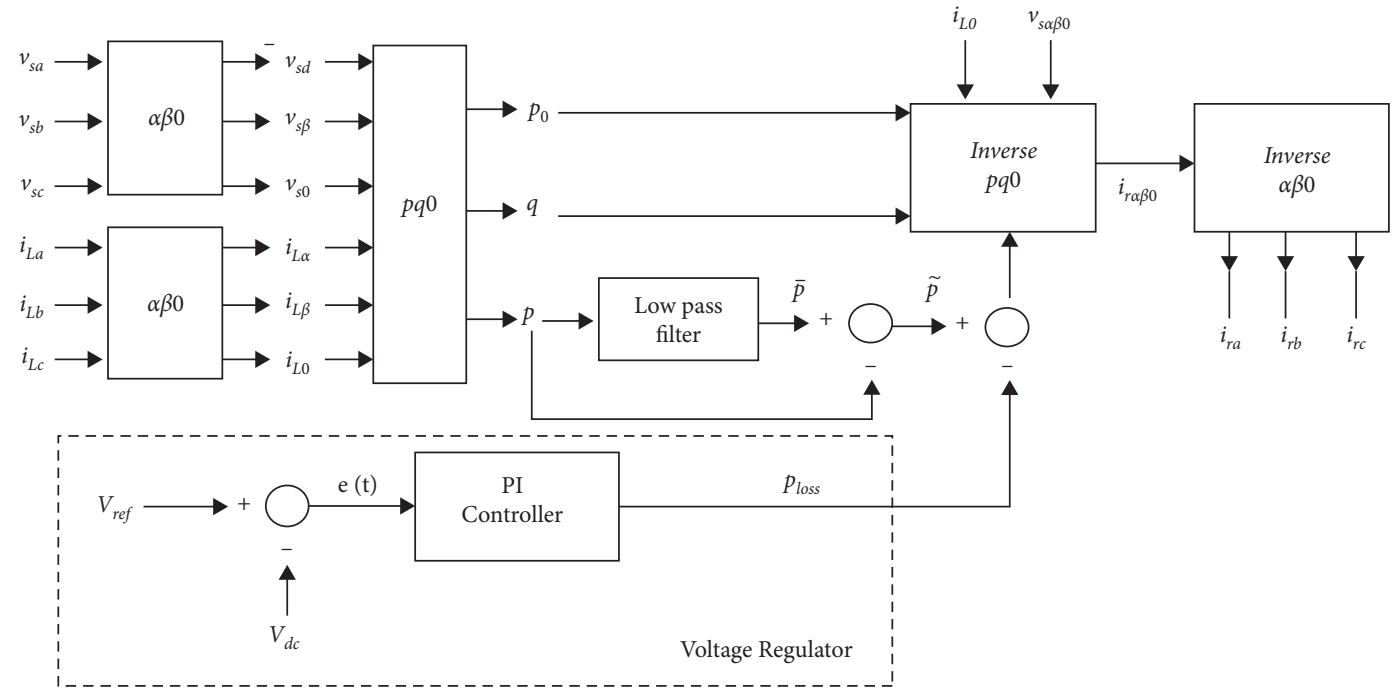

Figure 6: Pq0 theory-based detailed control activity.

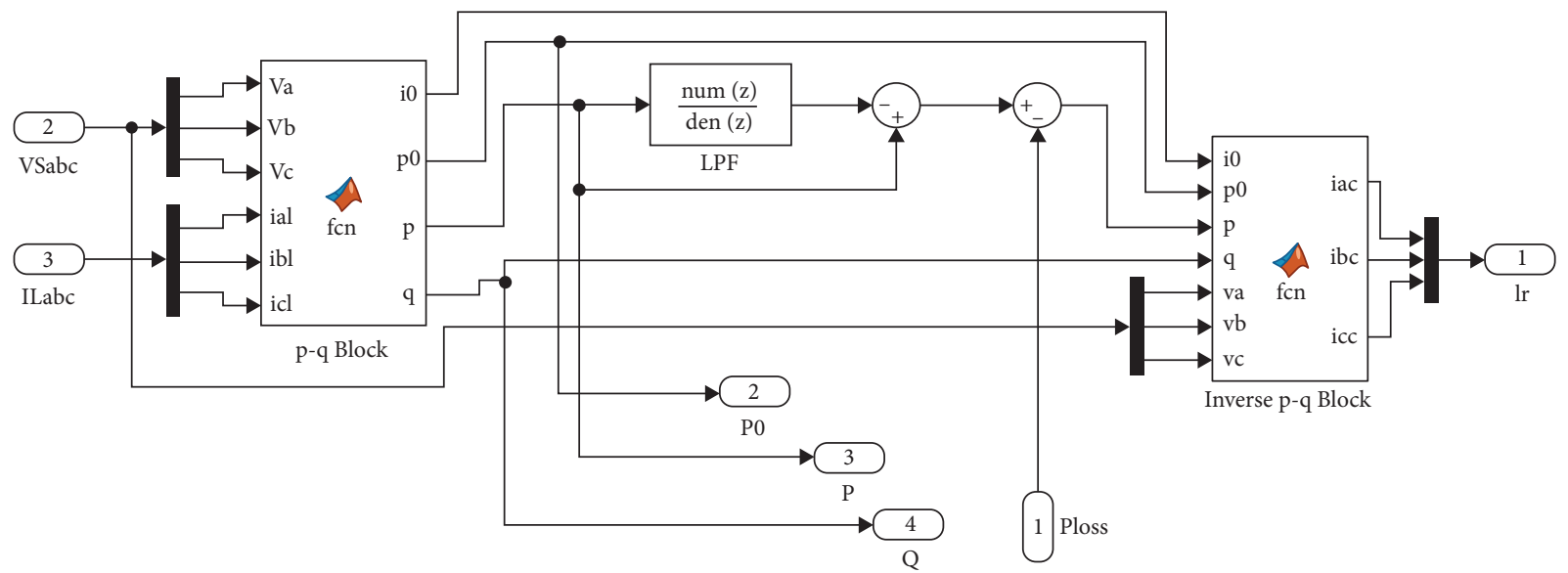

Figure 7: Implementation of Pq0-based control technique in Simulink.

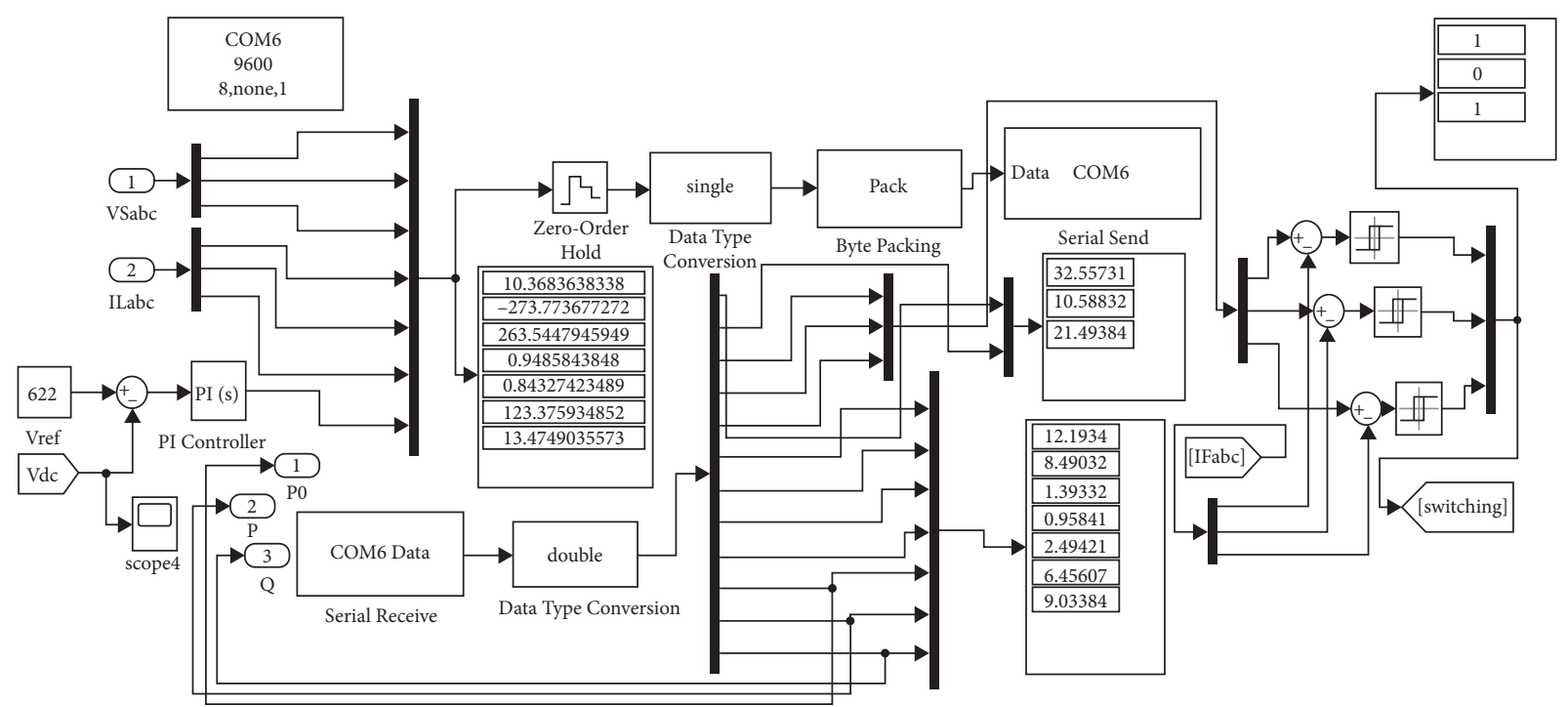

Figure 8: Run-time implementation of Pq0-based control algorithm in HIL. 


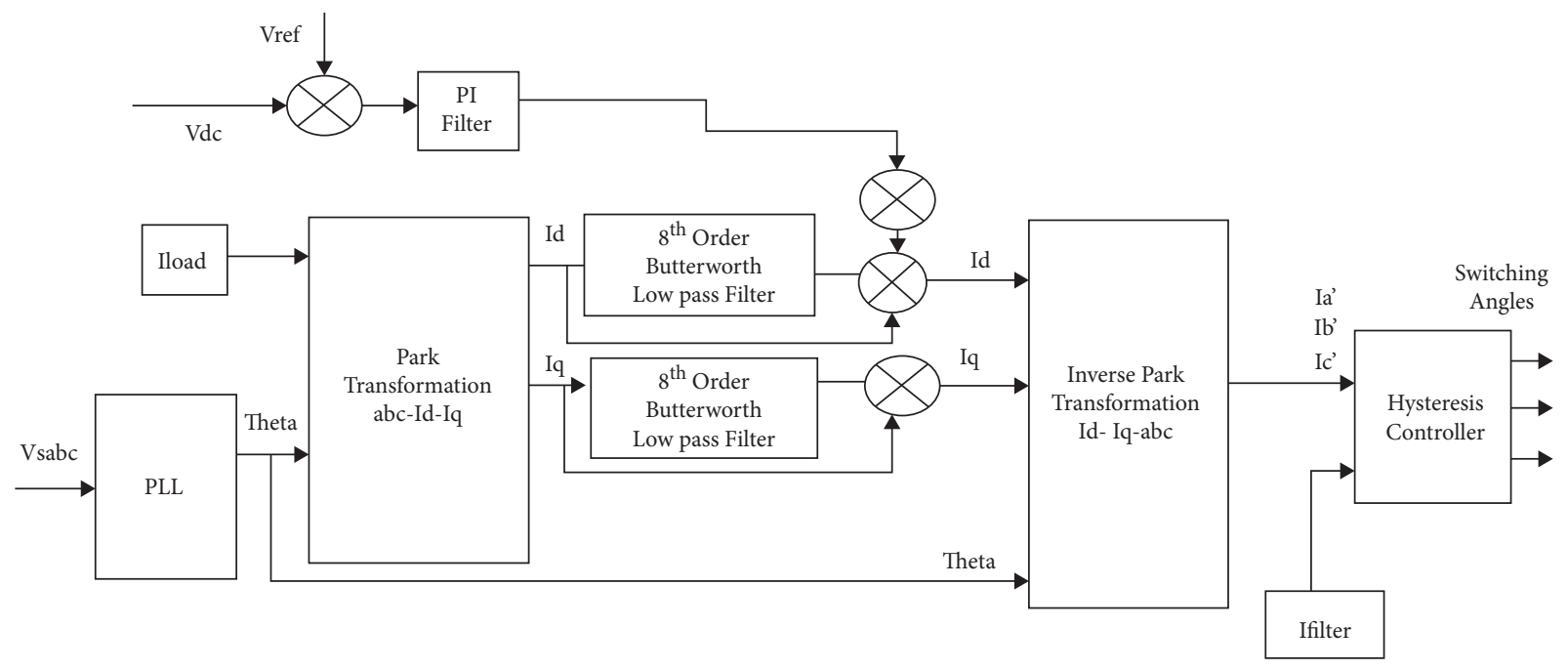

FIGURE 9: $I_{d}-I_{q}$ theory-based detailed control activity.

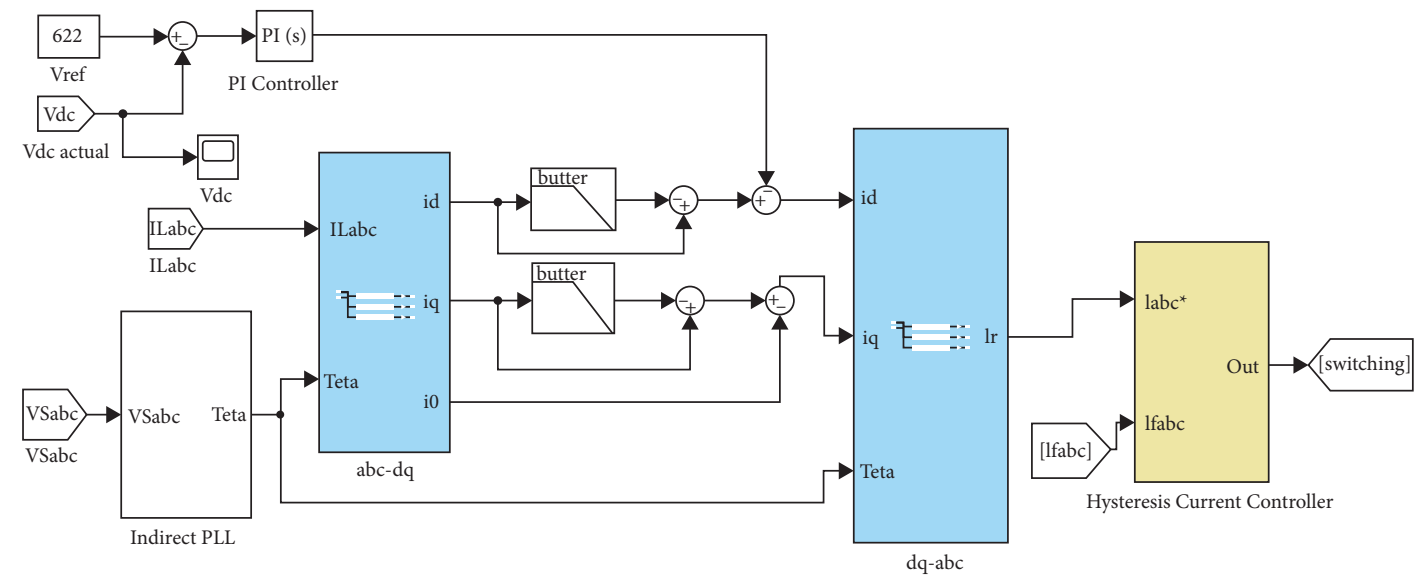

FIGURE 10: Implementation of $I_{d}-I_{q}$-based control technique in Simulink.

are converted into same data type and then sent as a single data type. The output is converted to a double on the receiving side then forwarded to a DEMUX (Figure 11).

2.4. Workflow Model of Controller HIL Testing Method. In the development process of HSAHPF, control algorithms were initially implemented in MATLAB/Simulink, and simulations are performed to observe the power behavior of the power simulator under various operating conditions. For the testing and verification of the hybrid power filter, the control algorithms were coded in IDE of Arduino that verifies the compatibility of Simulink with Arduino and validation of the power system using Arduino as controller HIL. This overall workflow model of the controller HIL simulator is depicted in Figure 12.

\section{Controller HIL Simulations and Results}

With the expansion of microcontrollers, portable microcontroller becomes an imperative way of verifying the control algorithms. The HIL structure comprises of actual hardware controller that interrelates with the remaining simulated system; it becomes controller hardware-in-theloop (CHIL). This research's primary objective was to implement both control algorithms in a controller HIL simulation setup, analyze their performance, and compare the results. In this controller HIL simulation technique, the control algorithms are programmed inside the IDE of Arduino, and after successful execution, the implemented C language code is uploaded to the Arduino. The setup is executed and calibrated. The sampling time is adjusted as the accuracy is highly sacrificed by increasing data rate and decreasing the number of samples. Therefore, the data rate and the number of samples were optimized to reduce the inaccuracy and improve efficiency. As the HSAHPF remains implemented in Simulink, the controller takes signals from Simulink and processes them inside Arduino using both the control algorithms to generate reference current signal and then referred to the simulator for proper switching and harmonics mitigation. A prototype of the implemented model is shown in Figure 13 that represents the HIL 


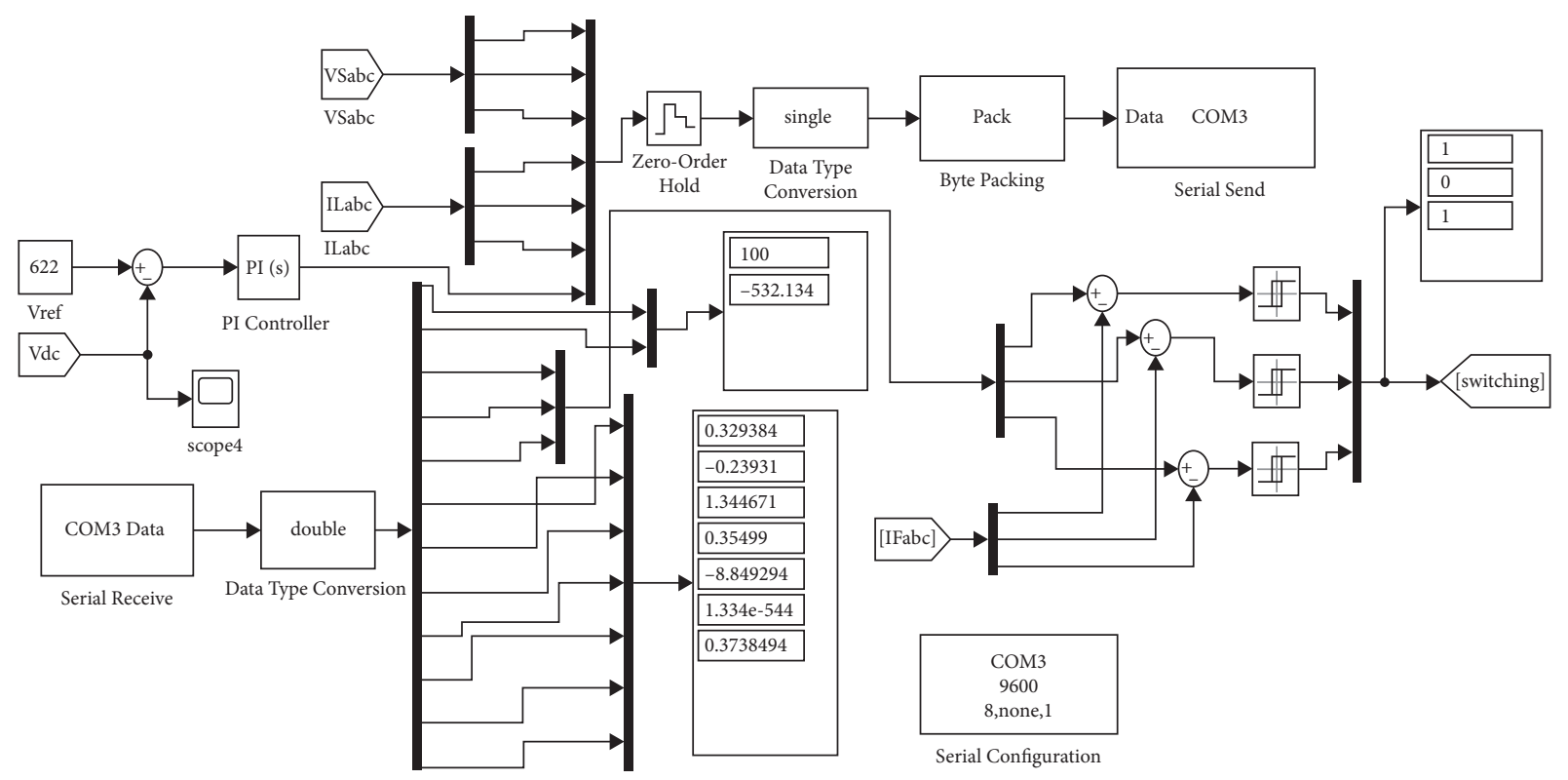

FIGURE 11: Implementation of $I_{d}-I_{q}$-based control algorithm in HIL.

implementation of high-power, three-phase HSAHPF in Simulink with controller HIL simulation for the monitoring and verification of the system.

3.1. Hardware-in-the-Loop Operation and Modeling. An Arduino application as a controller HIL platform for controlling a virtual plant (power electronics converter) implemented in the Simulink environment is presented in this paper. Although implemented control algorithms are not innovative, as the development of control methods for hybrid power filters is not the paper's aim, Arduino MEGA is chosen for the operation and monitoring of the system. The Tic Toc function in MATLAB is used for computing and monitoring the time for receiving data from Arduino. The data are exchanged synchronously and asynchronously.

In Simulink, Tic Toc functions are used to compute the time for receiving data from Arduino. The waveform of data receiving is obtained from the status scope, and for obtaining the time, the seconds data function is used. The scope shows the data receiving waveform while the seconds function depicts the time taken to receive the data. Figure 14 illustrates the run-time implementation of the $\mathrm{Pq} 0$ control technique in Simulink, representing the overall receiving time of data in Simulink from Arduino.

Six variables are sent from Arduino to Simulink and immediately back to monitor the overall time for this operation. All the simulations are run in nonblocking mode to obtain the waveforms of receiving time for data. From Figure 14, it can be observed that the total data receiving time in Simulink from Arduino is $0.2764 \mathrm{sec}$. Figure 15 represents the run-time data obtained in the $\mathrm{Pq0}$ control algorithm implemented in Arduino and the switching pulses to MOSFETS. The following graphs represent the amplitude versus time of the received signal in which Arduino sends the data to Simulink.
The I/O's of the external hardware controller connect with the system inside a simulator. The controller takes the simulator's feedback signal and processes it inside the controller to produce the required output and then sent back to the model implemented inside the simulator.

The data receiving time and its receiving status in the case of $I_{d}-I_{q}$ control algorithm implemented in Arduino and executed in Simulink can be observed in Figure 16. It depicts the receiving time of a single sample from Arduino in Simulink to be $0.00011 \mathrm{sec}$, while the total receiving time for data is $0.1938 \mathrm{sec}$ for the $I_{d}-I_{q}$ control technique in Simulink. Initially, the calculation of sending and receiving time will be observed in Arduino. Starting within the setup pins are initialized as output so that they can be used to display waveforms. The built-in function micro () is used, and the current time is measured, and then it is subtracted from the last time to get the time taken to send, receive, and the overall execution time. Next, the assigned digital pins, high and low, are used when the data are received and sent. The digital pins will provide the waveforms, and the time of data sending and receiving is calculated and displayed in Simulink. Figure 17 depicts the amplitude versus time graph representing the reliable waveform for received data time in Simulink and the switching pulses to MOSFETS.

3.2. Pq0 Control Technique Implemented in Simulink. The following results will be obtained when both the power circuit of HSAHPF using three-phase, four-wire and control techniques have been implemented in Simulink. The source current waveform becomes sinusoidal with $3.14 \%$ THD at $50 \mathrm{~Hz}$ fundamental frequency as depicted in Figure 18, showing the contribution of the first 20 harmonics in the system. The overall system responses are as follows:

Figure 19(a) represents the source current harmonics when the Pq0 control technique is implemented in Simulink. 


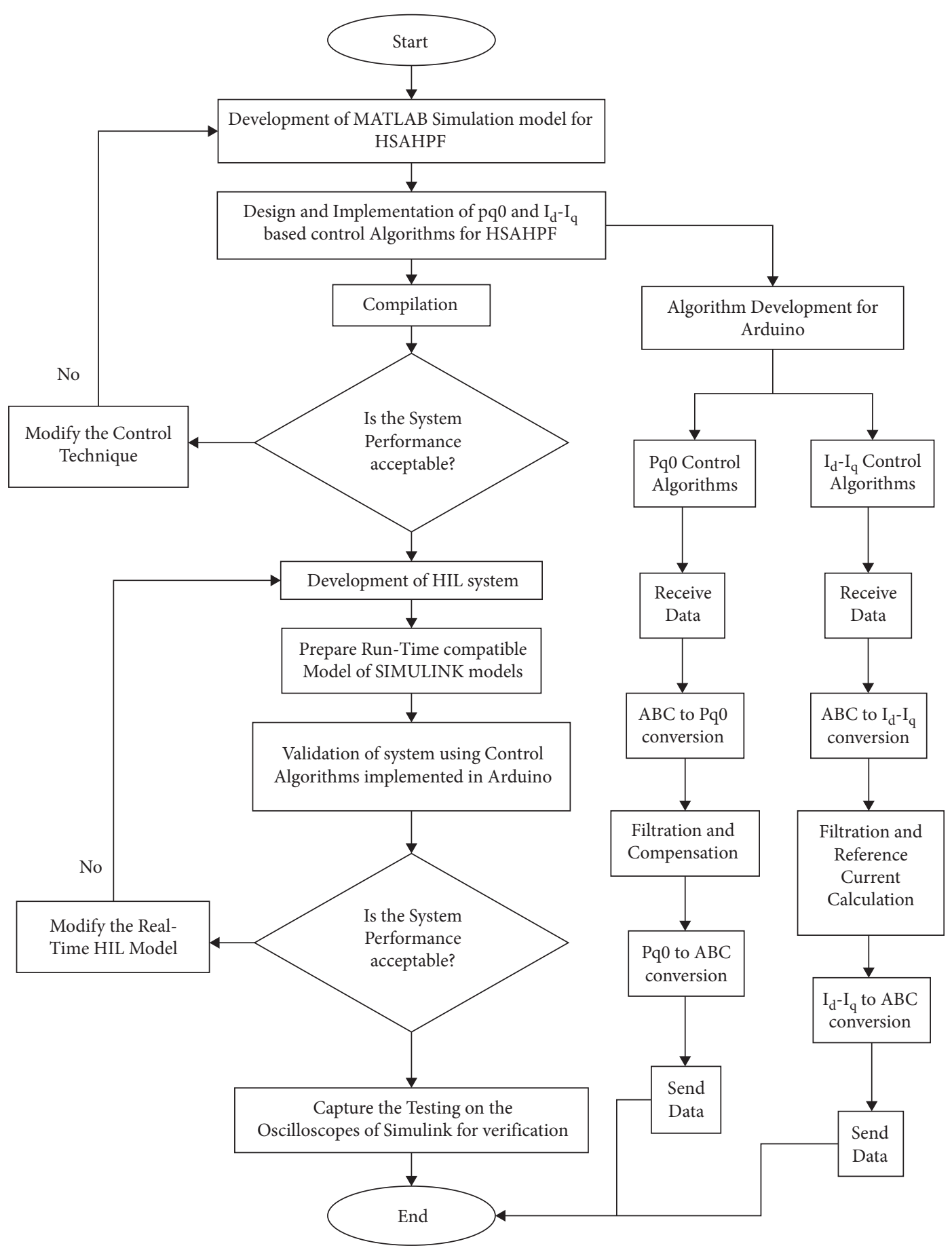

Figure 12: Flowchart of HSHAPF using controller HIL simulations.

It can be observed that the waveform becomes sinusoidal without distortions after achieving its stability time of $0.06 \mathrm{~s}$ that effectively compensates for the harmonic distortion under balanced loading conditions present in the supply current. Figure 19(b) represents the source voltage harmonics that are purely sinusoidal due to the balanced load. Figure 19(c) represents the load current waveform, where it is observed that due to the nonlinear load attached with the system, the obtained current is not purely sinusoidal due to the presence of harmonics. It also contains positive and negative spikes due to the charging and discharging of the capacitor. The nonlinear load is continuously attached to the system, so there is no need to eliminate load current harmonics. The harmonics always travel from the nonlinear load side to the source side; they are mitigated at the PCC source side to achieve good-quality power.

The current after passing through a passive filter as a result of harmonic current detection using the $\mathrm{Pq} 0$ control theory is shown in Figure 9(d). For diminishing the neutral wire current, reduction in harmonics plays a significant role 


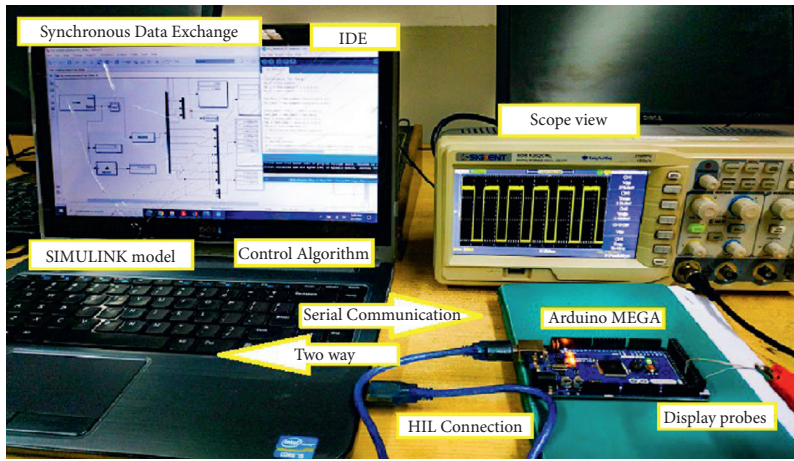

FIGURE 13: Experimental setup of implemented hardware-in-the-loop model.

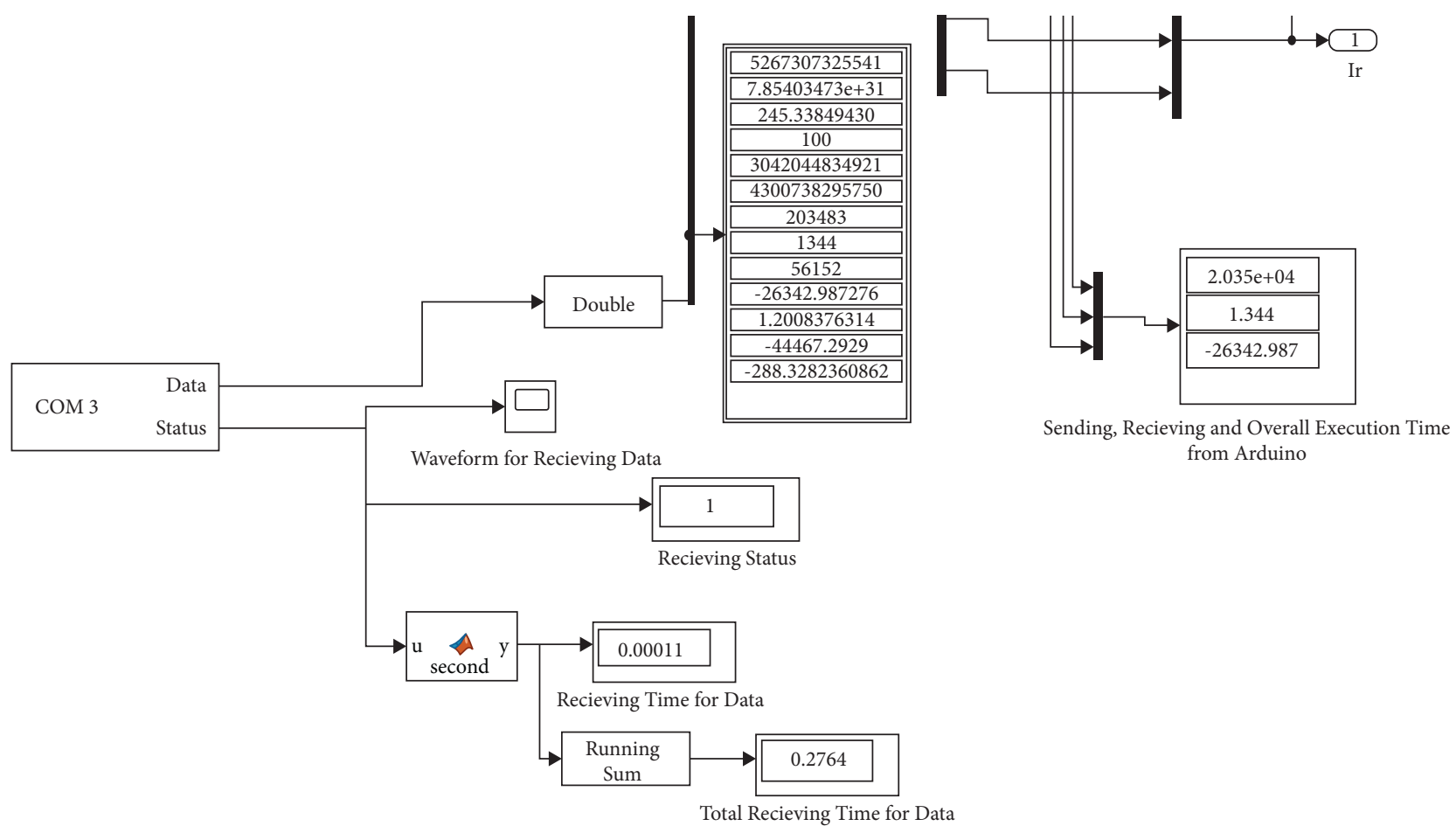

Figure 14: Monitoring of data and execution time of Pq0 control algorithm.

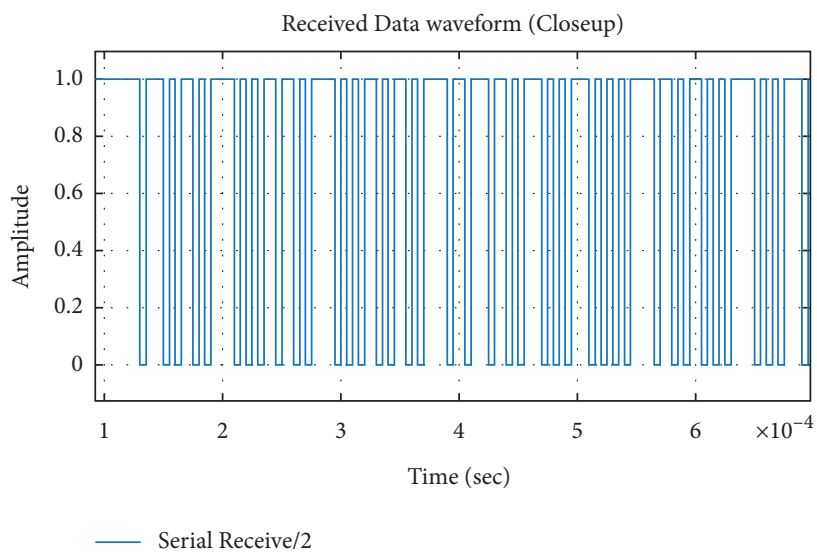

FIGURE 15: The received data waveform from Arduino to Simulink for Pq0 control algorithm. in reducing the neutral wire current from $12 \mathrm{~A}$ to $0.9 \mathrm{~A}$. When the Pq0 control technique is implemented for a balanced load in Simulink, the neutral wire current for the load and source side is depicted in Figure 19(e), reducing the neutral wire current towards the source side. The voltage regulator is regulated using the PI controller to minimize the switching losses of the VSI; thus, it charges the DC capacitors on discharging. Initially, the regulator's behavior is unstable, but at $0.06 \mathrm{~s}$, it becomes stable, as shown in Figure 19(f), which concludes that HSAHPF has maintained the DC-link voltage constant.

3.3. Pq0 Control Algorithm Implemented in Arduino. When the power circuit of three-phase four-wire HSAHPF is implemented in Simulink, the Pq0 control algorithm is programmed in the Arduino MEGA 2560 using hardware-in-the- 


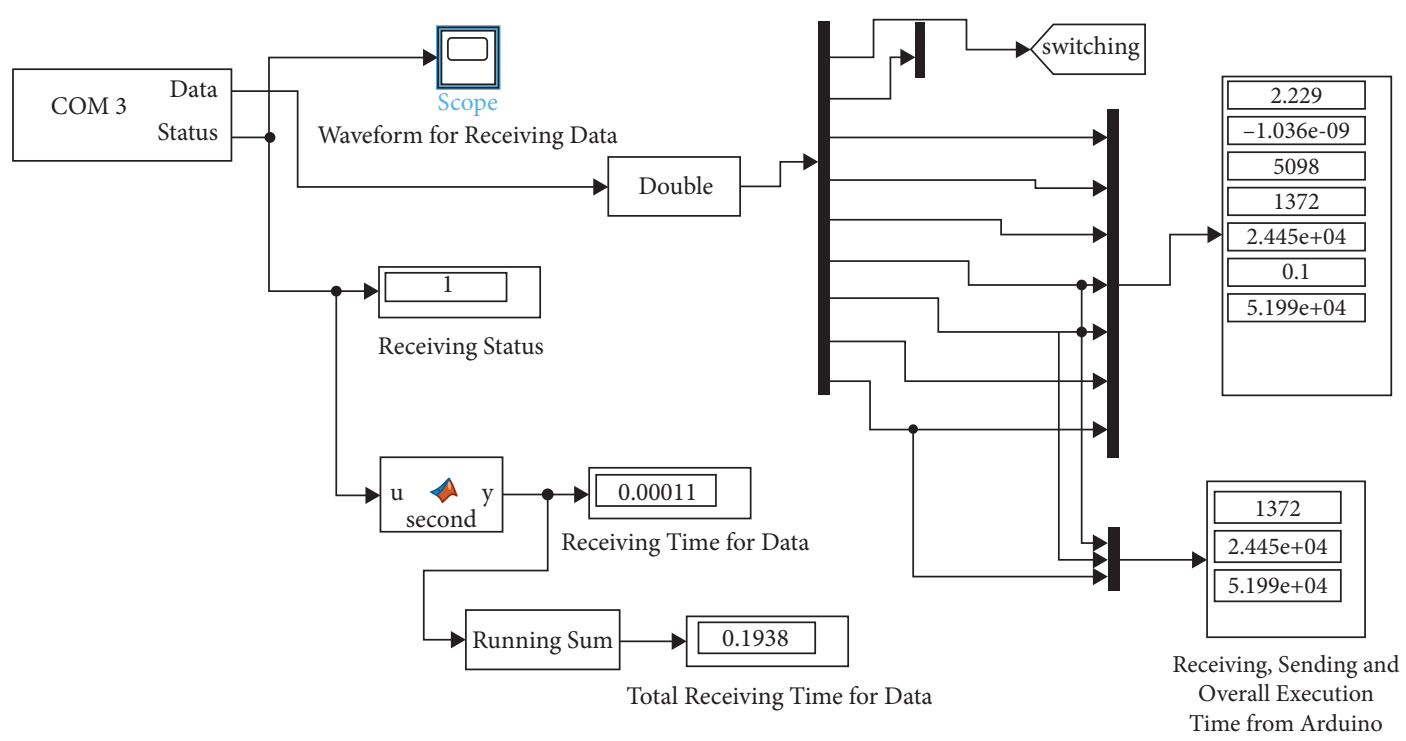

FIgURE 16: Monitoring of data and execution time of $I_{d}-I_{q}$ control algorithm.

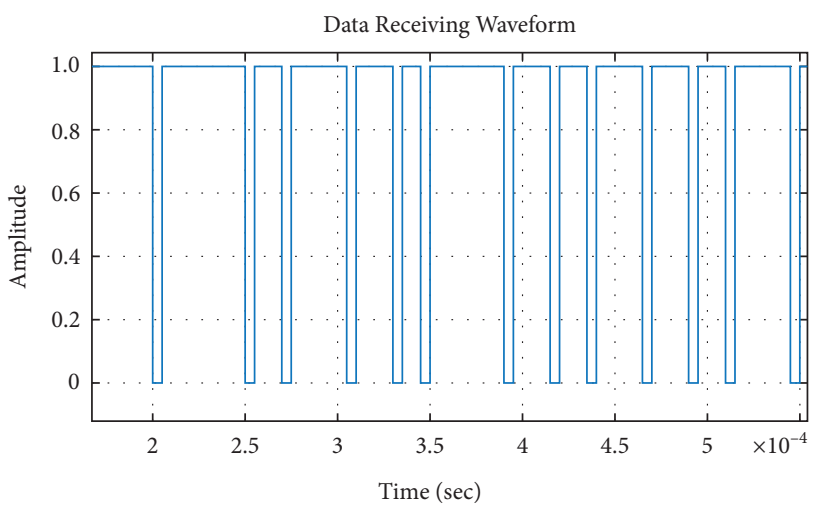

FIGURE 17: Received data waveform from Arduino to Simulink for $I_{d}-I_{q}$ control algorithm.

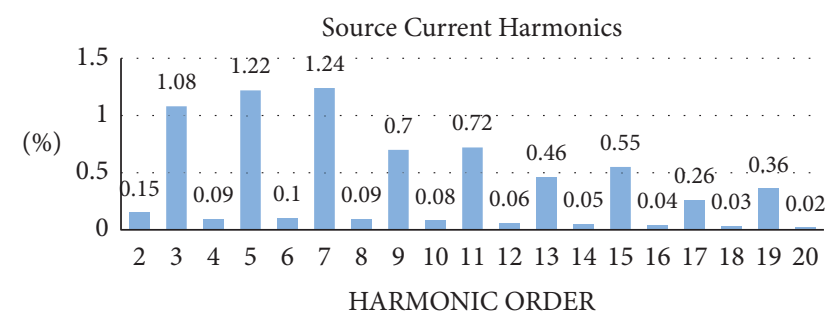

Figure 18: Source current harmonics using Simulink-based Pq0 control technique.

loop simulation. The simulation results of source current, source voltage, load current, filter current, neutral wire current, and DC-link voltage are shown below, as the implemented Pq0 control algorithm in Simulink. The sinusoidal waveforms for source current and voltages of the system with $\mathrm{Pq} 0$ control algorithm implemented in Arduino MEGA-based HSAHPF are shown in Figures 20(a) and 20(c), respectively. Figure 20(b) represents the load current waveform using Arduino-based Pq0 control technique that is nonsinusoidal containing positive and negative peaks for charging and discharging of the capacitors.

The system's obtained sinusoidal waveforms for source current $\left(I_{s a b c}\right)$ and voltages $\left(V_{s a b c}\right)$ with $\mathrm{Pq} 0$ control algorithm implemented in Arduino MEGA, based on HSAHPF are shown earlier. It can be observed from these waveforms that harmonics are eliminated, and the source current does not contain any distortions and spikes after achieving its stability time. The filter current obtained using the Arduino-based Pq0 control algorithm in Figure 20(d) depicts that the waveform still contains distortions due to the impedance of a single tuned passive filter. It was dependent on the inductance, capacitance, and resistance of the attached nonlinear load. The difference in neutral wire current for load and source side is depicted in Figure 20(e) which clearly shows the reduction of current for neutral wire towards the source side. The voltage regulator is regulated using a PI controller in the inner control loop to reduce the inverter's switching losses. Initially, it contains continuous fluctuations, but it becomes stable at $0.06 \mathrm{~s}$, as shown in Figure 20(f). Due to the limitation, the $I_{d}-I_{q}$ control technique is implemented that provides sinusoidal filter current.

\subsection{System Response Using the $I_{d}-I_{q}$ Control-Based HSAHPF} Implemented in Simulink. The following results have been obtained when the power circuit using three-phase, three-wire HSAHPF and control techniques have been implemented in Simulink. Figure 21 represents the occurrence of even and oddorder harmonics after $I_{d}-I_{q}$ implementation and shows the contribution of the first 20 harmonics in the system to be mitigated accordingly.

When the $I_{d}-I_{q}$ control technique is implemented in Simulink, the source current becomes sinusoidal with $2.01 \% \mathrm{THD}$ at $50 \mathrm{~Hz}$ fundamental frequency, as depicted by Figure 21 . The results also show that $I_{d}-I_{q}$ can compensate harmonics and reactive power components, thus enhancing the power factor as it works in a rotating 


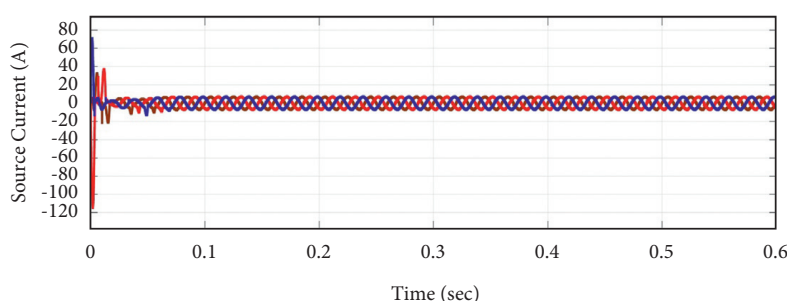

(a)

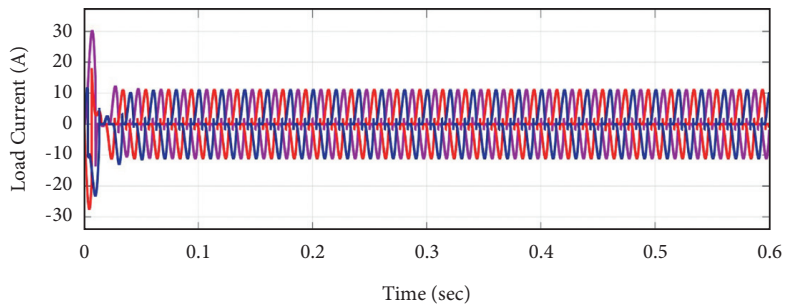

(c)
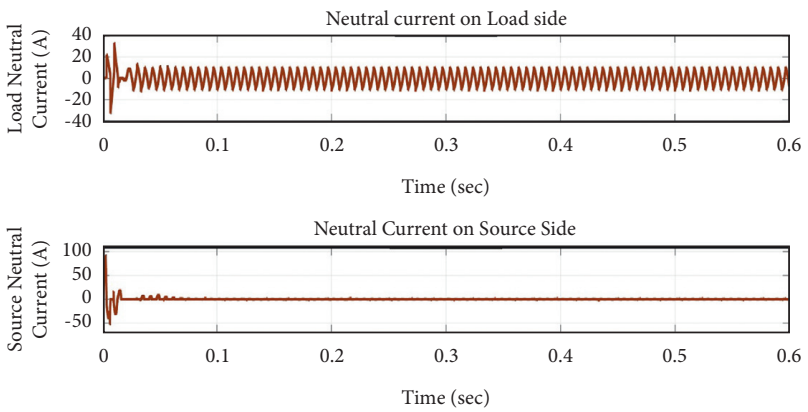

(e)

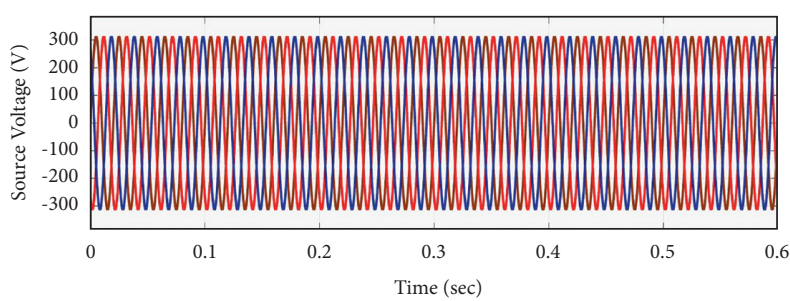

(b)

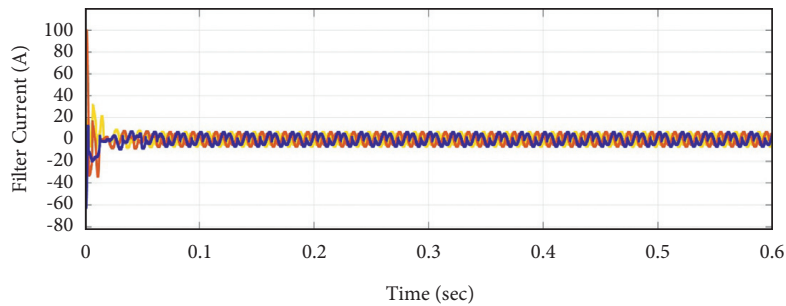

(d)

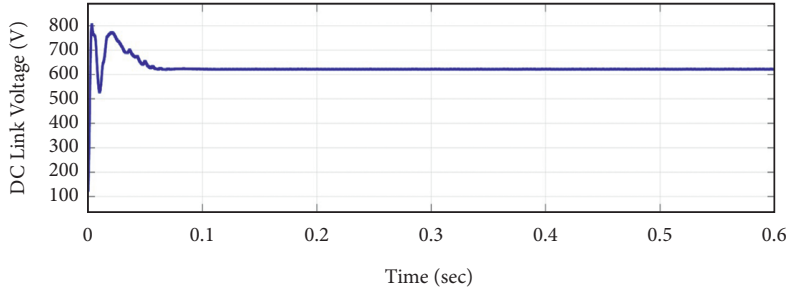

(f)

FIgURE 19: (a) Source current waveform using Simulink-based Pq0 control technique. (b) Source voltage waveform using Simulink-based Pq0 control technique. (c) Load current waveform using Simulink-based Pq0 control technique. (d) Filter current using Simulink-based Pq0 control technique. (e) Neutral wire current using Simulink-based Pq0 control technique. (f) Regulated DC-voltage using Simulink-based $\mathrm{Pq} 0$ control technique.

reference frame. Due to the presence of a balanced threephase nonlinear load, and as the voltage harmonics are controlled by maintaining the source impedance, there are no distortions in source voltage waveforms.

From Figure 22(a), the transient response of source current can be observed. Initially, it contains oscillations, and then the system becomes stable after $0.1 \mathrm{~s}$. Figure 22(b) represents the load current in the case of a three-phase, three-wire system when the attached load is a single rectifier across all three phases instead of a combination of three single-phase rectifiers. The filter current obtained through this technique is nearly sinusoidal but contains overshoot till achieving its stability time and can be seen in Figure 22(c). The sinusoidal waveform for source voltage of the system, when the $I_{d}-I_{q}$ control technique is implemented in Simulink-based HSAHPF is shown in Figure 22(d). The voltage regulator is controlled using a PI controller to reduce the inverter's switching losses and charge the DC capacitors when discharged. From the results in Figure 22(e), it is observed that the stability time of the regulator is further improved to $0.03 \mathrm{~s}$ using this technique that is better than the stability time achieved in the case of the Pq0 control algorithm.
3.5. System Response Using the $I_{d}-I_{q}$ Control-Based HSAHPF Implemented in Arduino. Once the power circuit of threephase, three-wire HSAHPF is implemented in Simulink, the control algorithms are programmed in Arduino, so the overall system acts as HIL. Actual power transfer would not happen in this method. The power system will be shown as a virtual system within the simulator; therefore, extrinsic hardware controller exchanging I/O's of the controller with the structure modeled in Simulink. Results and simulations are shown below that are similar to the overall system implemented in Simulink. The obtained source current in Figure 23(a) and source voltages in Figure 23(d) become sinusoidal after achieving their stability time. The load current in Figure 23(b) is nonsinusoidal that is the main cause of harmonics in the system. The obtained filter current is sinusoidal that also verifies the performance of the implemented technique and can be observed in Figure 22(c).

The achieved filter current across all three phases using Arduino-based $I_{d}-I_{q}$ is sinusoidal and balanced, representing the passive filter's good compensation performance. Figures 23(a) to 23(e) depict that the $I_{d}-I_{q}$ control technique has more efficient results with improved THD; thus, it 


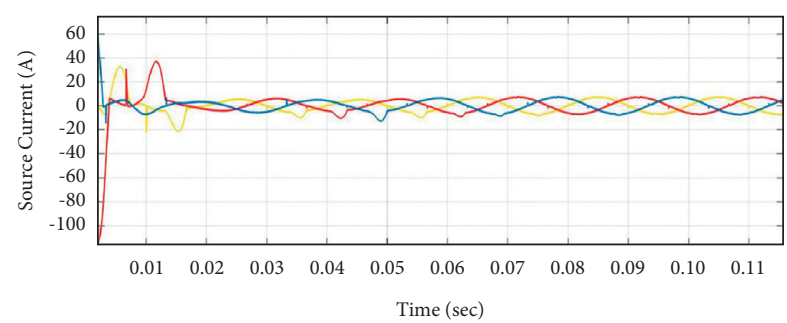

(a)

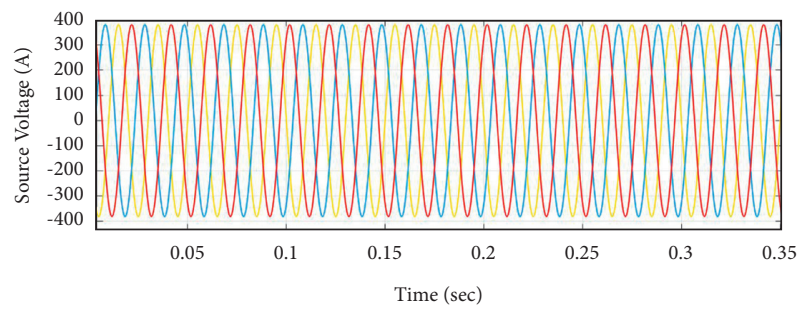

(c)

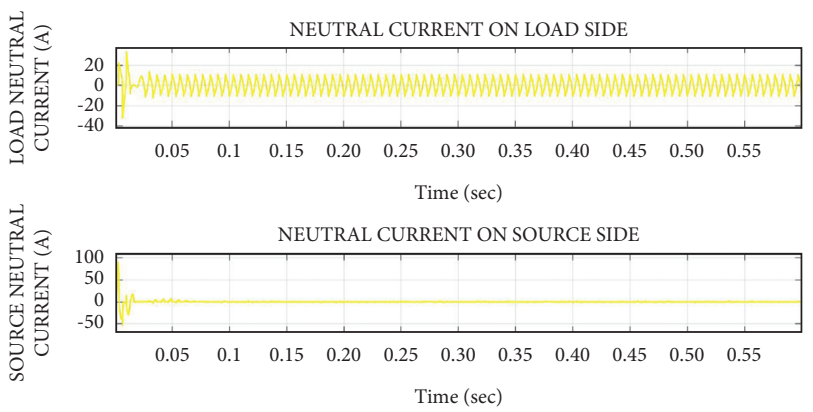

(e)

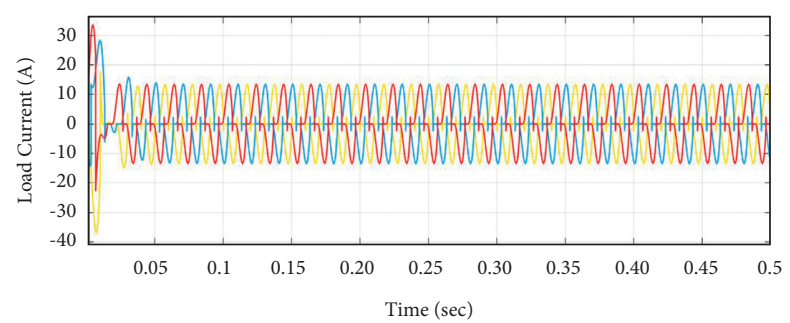

(b)

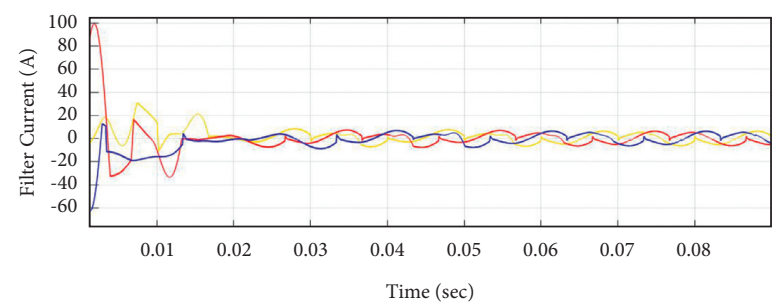

(d)

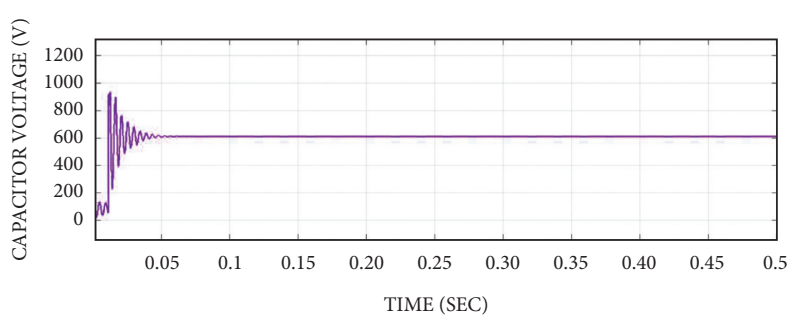

(f)

FIgURE 20: (a) Source current waveform using Arduino-based Pq0 control technique. (b) Load current waveform using Arduino-based Pq0 control technique. (c) Source voltage waveform using Arduino-based Pq0 control technique. (d) Filter current using Arduino-based Pq0 control technique. (e) Neutral wire current using Arduino-based Pq0 control technique. (f) Regulated dc-voltage using Arduino-based Pq0 control technique.

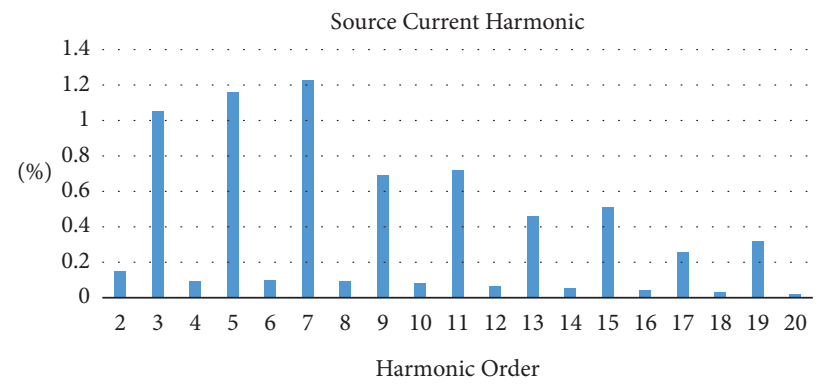

FIGURE 21: Source current harmonics using Simulink-based $I_{d}-I_{q}$ control technique.

verifies that the controller HIL simulation ensures reliability and quality. The obtained results confirm that the controller HIL simulation is an efficient testing and monitoring technique that can send and receive data via serial communication without losing information by adjusting the data rate and the number of samples.

\section{Results Discussion and Comparative Analysis}

The compensation performance of HSAHPF is verified through the harmonic spectrum of $I_{s a b c}$, shown in Figure 13, and it is detected that THD of $I_{s a b c}$ of three-phase, four-wire HSAHPF system, on the whole, is found to be $3.12 \%$ in case 


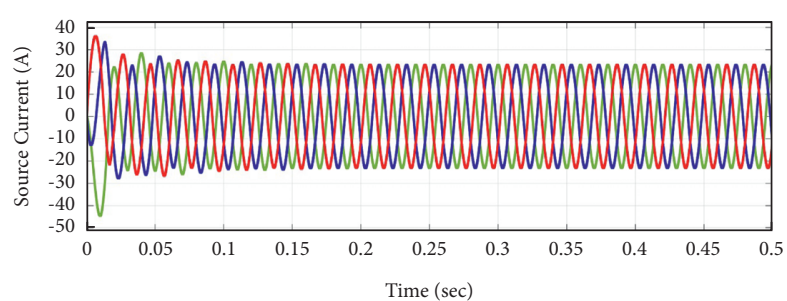

(a)

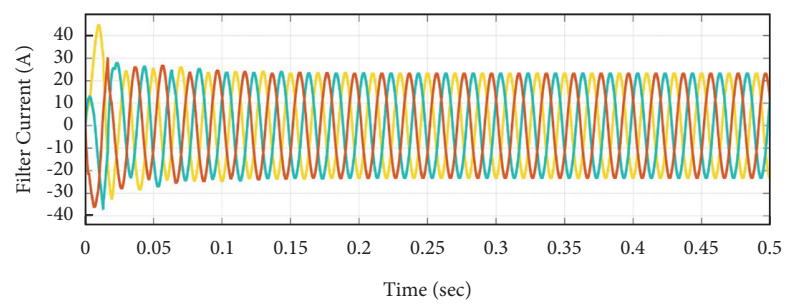

(c)

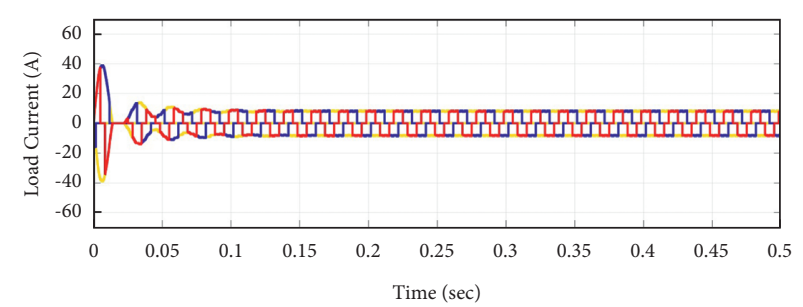

(b)

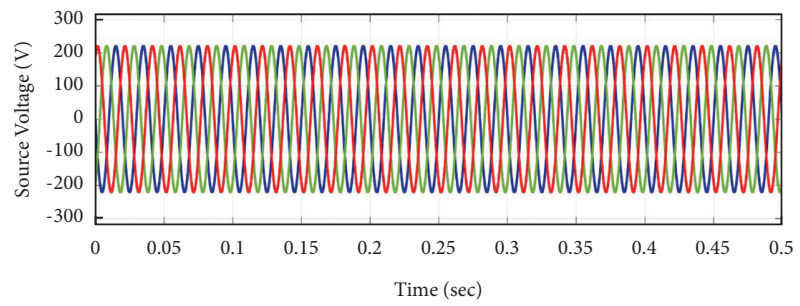

(d)

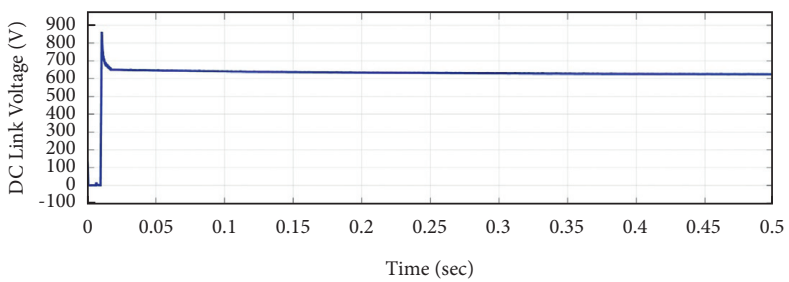

(e)

FIGURE 22: (a) Source current waveform using Simulink-based $I_{d}-I_{q}$ control technique. (b) Load current waveform using Simulink-based $I_{d}-I_{q}$ control technique. (c) Filter current using Simulink-based $I_{d}-I_{q}$ control technique. (d) Source voltage using Simulink-based $I_{d}-I_{q}$ control technique. (e) Regulated dc-voltage using Simulink-based $I_{d}-I_{q}$ control technique.

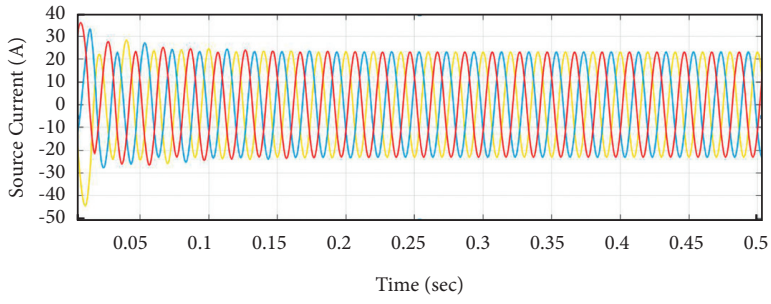

(a)

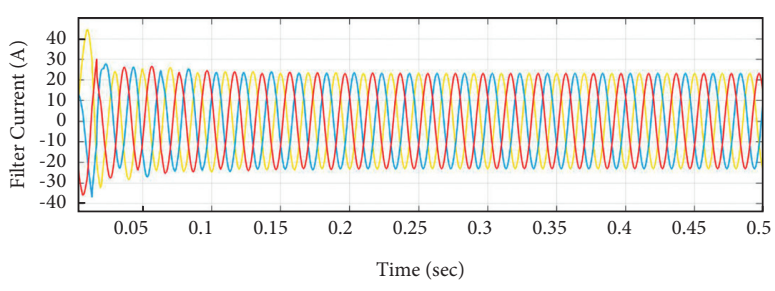

(c)

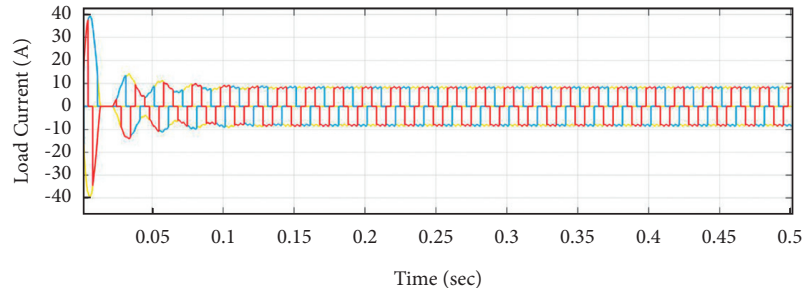

(b)

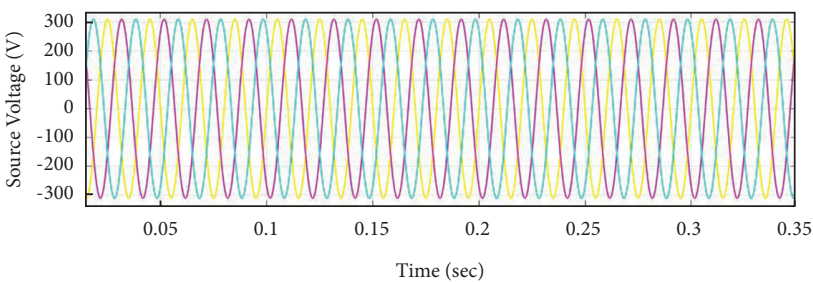

(d)

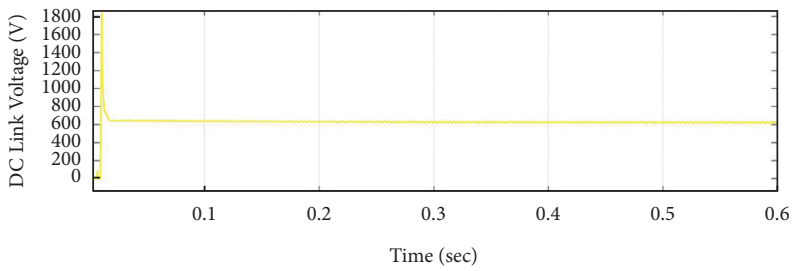

(e)

Figure 23: (a) Source current waveform using Arduino-based $I_{d}-I_{q}$ control technique. (b) Load current waveform using Arduino-based $I_{d}-I_{q}$ control technique. (c) Filter current using Arduino-based $I_{d}-I_{q}$ control technique. (d) Source voltage using Arduino-based $I_{d}-I_{q}$ control technique. (e) Regulated dc-voltage using Arduino-based $I_{d}-I_{q}$ control technique. 

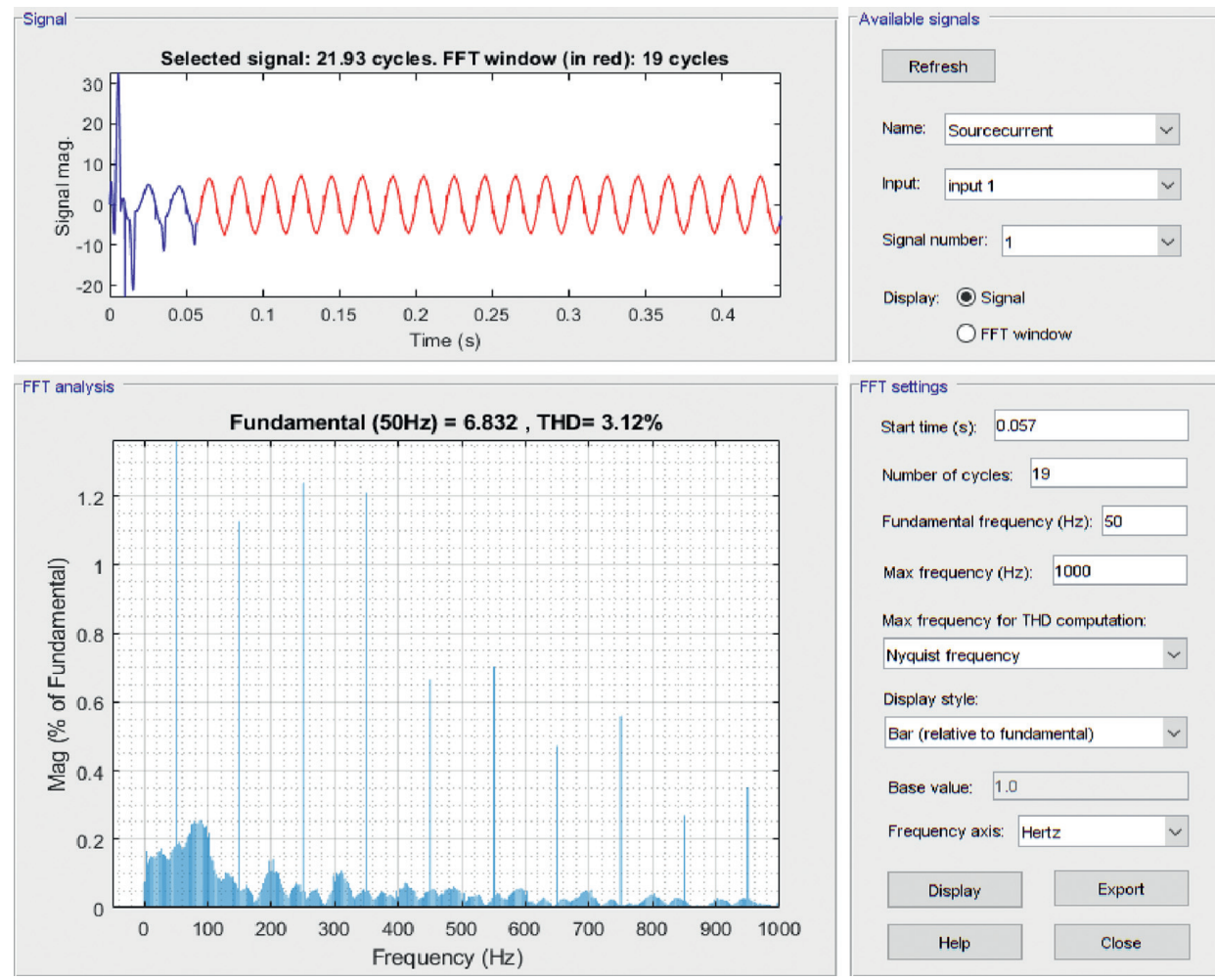

(a)
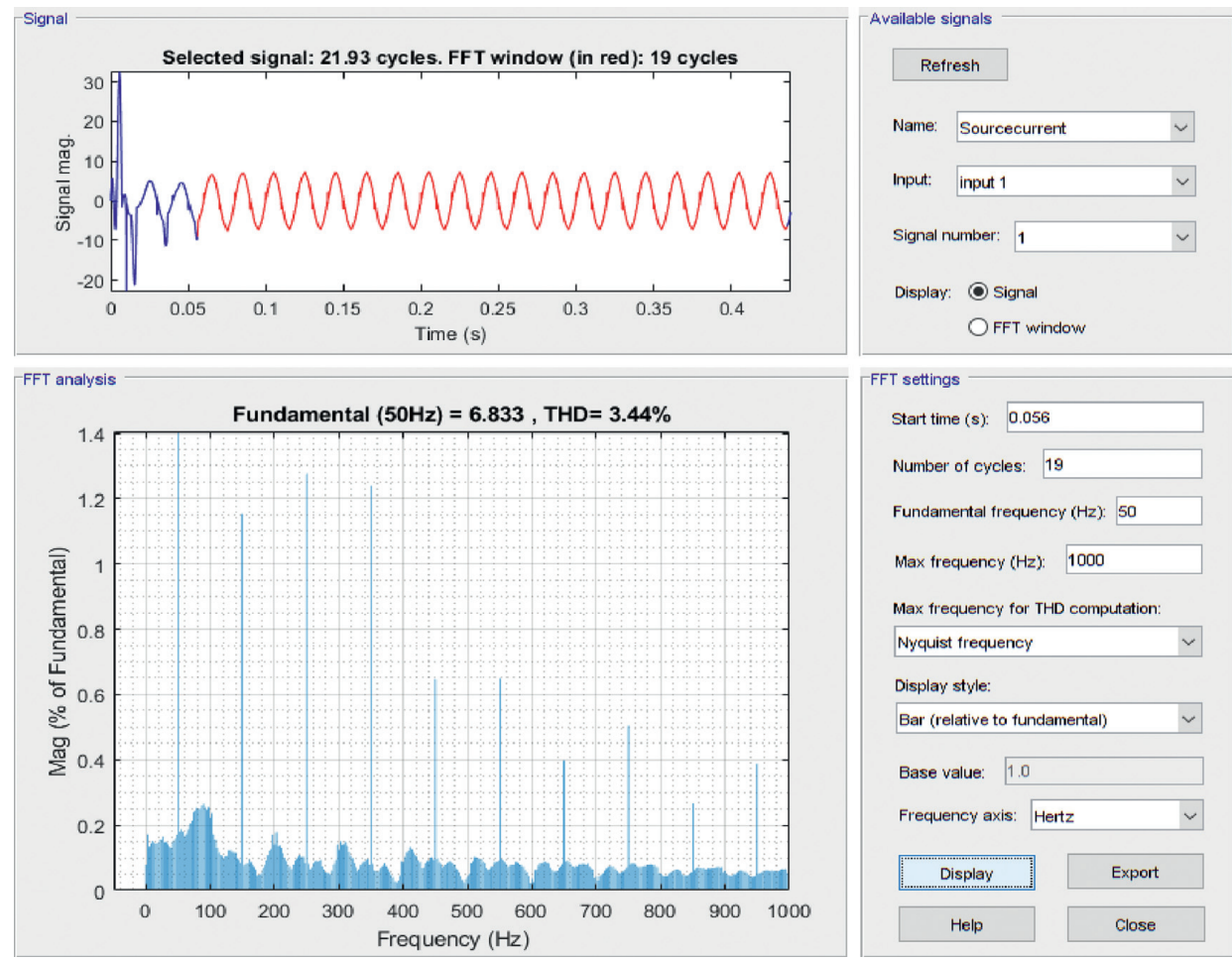

(b)

Figure 24: (a) FFT spectrum of Simulink-based source current using Pq0 control technique. (b) FFT spectrum of Arduino-based source current using Pq0 control technique. 

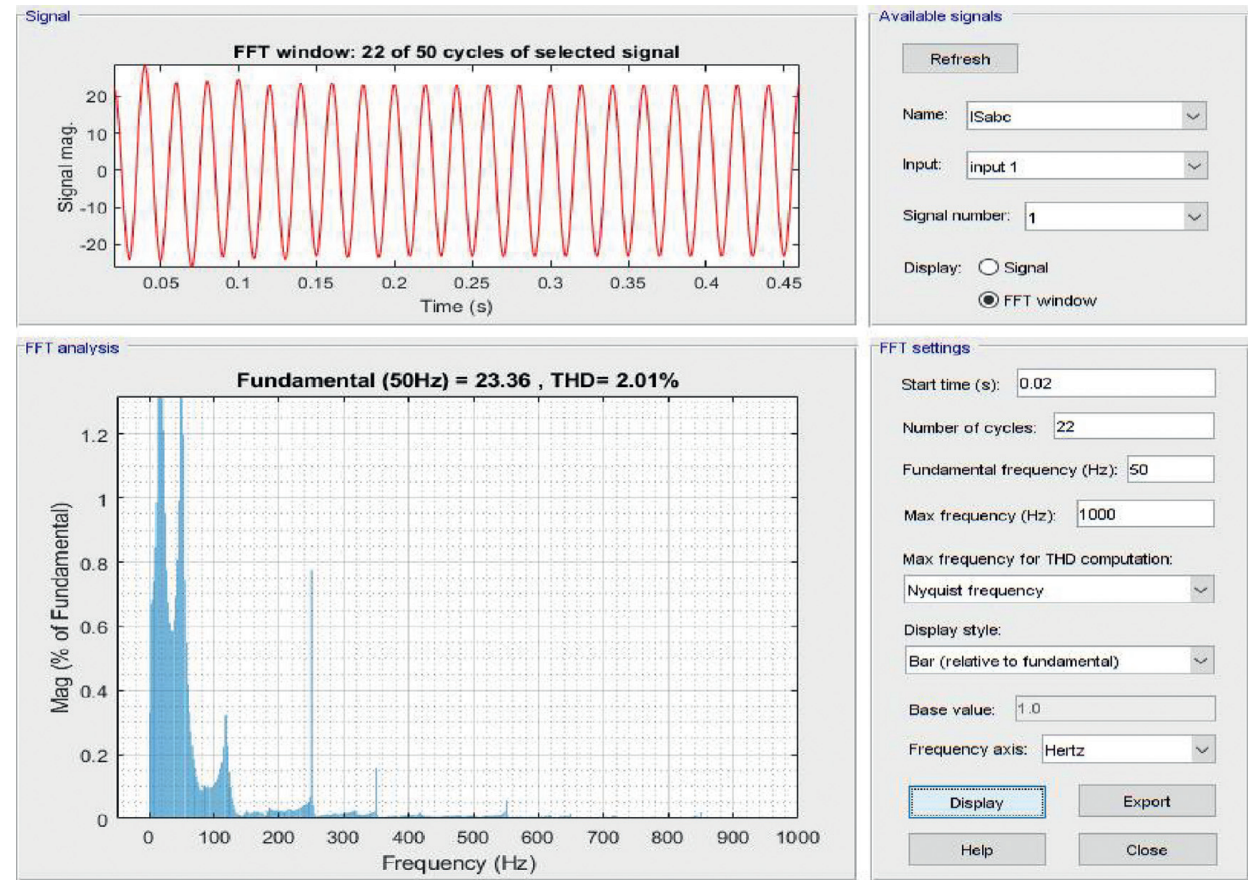

(a)
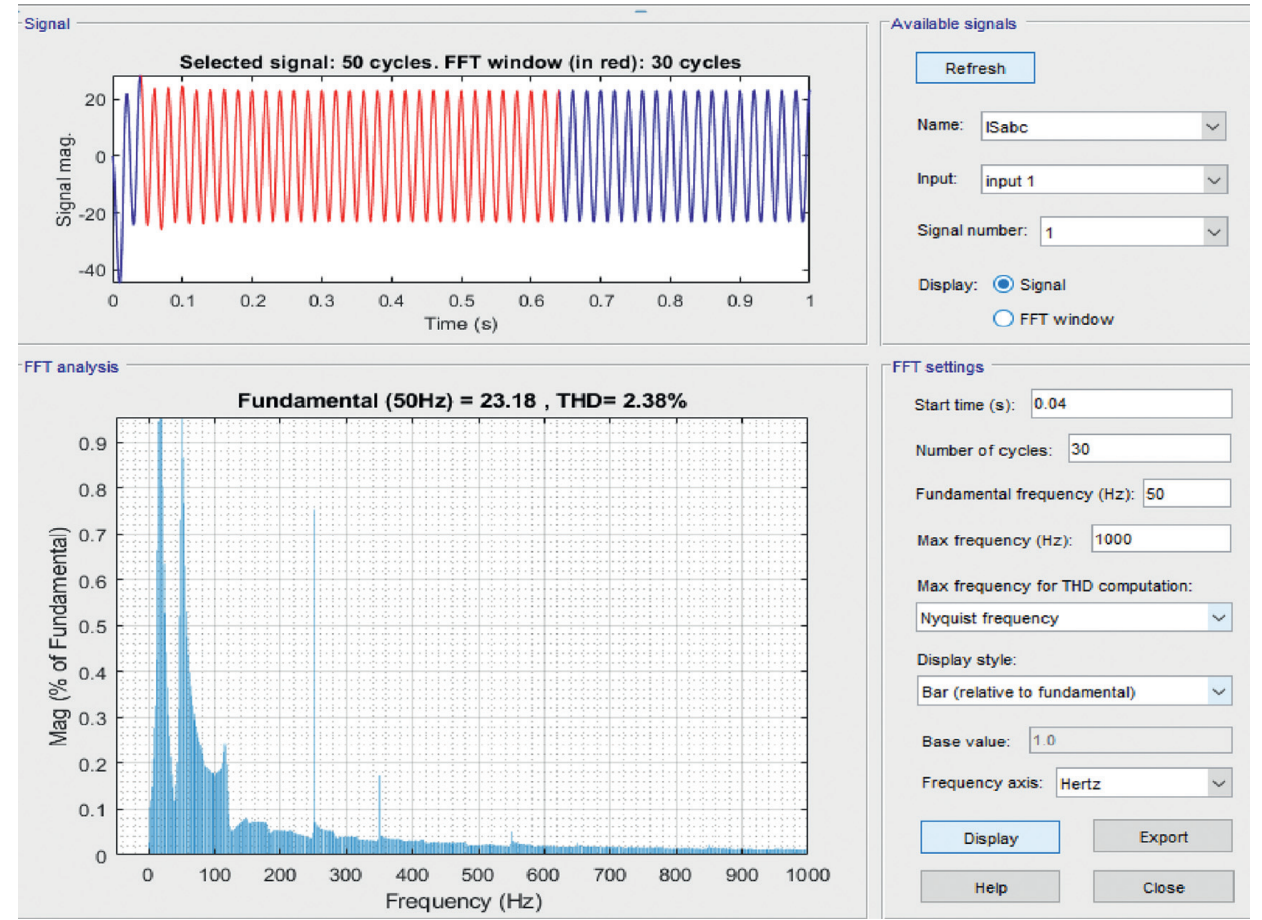

(b)

FIGURE 25: (a) FFT spectrum of Simulink-based source current using $I_{d}-I_{q}$ control technique. (b) FFT spectrum of Arduino-based source current using $I_{d}-I_{q}$ control technique.

of Simulink-based implementation and 3.44\% in case of Arduino-based implementation that lies in the required range set by the international standards to meet IEEE 5191992 for current harmonics. While initially, it was found to be 35.84 when no control technique was applied. After implementing HSAHPF using the Pq0 control algorithm based on the HIL technique, the achieved stability time of source current is $0.05 \mathrm{~s}$, and it can be observed in Figures 24(a) and 24(b).

Overall, the compensation performance of HSAHPF is verified, as the harmonic spectrum of $I_{\text {sabc }}$ is presented below figures, and it is detected that THD of $I_{s a b c}$ of three-phase, 
TABle 2: Comparative analysis of the control techniques in this research work for HSAHPF.

\begin{tabular}{lcccc}
\hline Control techniques & \multicolumn{3}{c}{ Parameters } \\
& THD (\%) & Stability time (sec) & Sampling time (sec) & Power factor \\
\hline Pq0 implemented in Simulink & 3.12 & 0.06 & $5 e-08$ & 0.998 \\
Pq0 implemented in Arduino & 3.44 & 0.06 & $5 e-06$ & 5.982 \\
$I_{d}-I_{q}$ implemented in Simulink & 2.01 & 0.03 & $5 e-08$ & 1 \\
$I_{d}-I_{q}$ implemented in Arduino & 2.38 & 0.04 & $5 e-06$ & 0.993 \\
\hline
\end{tabular}

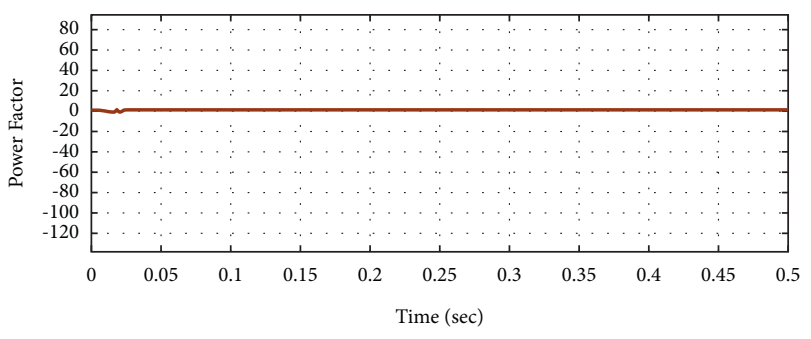

FIGURe 26: Power factor waveform verifying the performance of HSAHPF.

three-wire HSAHPF system, on the whole, is found to be $2.01 \%$ in case of Simulink-based control technique and $2.38 \%$ in case of Arduino-based control algorithm that is reduced from 31.76 that also meet IEEE 519-1992 for current harmonics and can be observed in Figures 25(a) and 25(b).

The stability time of source current is further improved to $0.04 \mathrm{~s}$ using this technique. Conventional power systems and real-time simulating tools, such as RTDS and Opal-RT, are inadequate because of low switching frequency and high cost. Arduino, an open-source electronics platform, is an innovative technique that contains the coded control algorithm in its open-source Arduino software (IDE). It plays an essential role as a test platform when interfaced with Simulink/MATLAB. Both control algorithms are programmed in $\mathrm{C}$ language using Arduino with IDE as development software to verify HSAHPF. It proves to be costeffective, portable, and ideal testing equipment. For ascertaining the actual application and effectiveness of the proposed control algorithms, Arduino is used as an external hardware controller to verify the performance of HSAHPF. The comparative analysis is shown in Table 2 in terms of THD, stability time, power factor, and sampling time (accuracy).

It is verified that the proposed HSAHPF can restore the actual sinusoidal current and voltages by upholding the voltage regulator's stability time to $0.06 \mathrm{~s}$ in the case of $\mathrm{Pq} 0$ control technique $0.04 \mathrm{~s}$ in the case of the $I_{d}-I_{q}$ control algorithm. The attained power factor in $I_{d}-I_{q}$ 's case is unity, and THD is 2.01, which is more efficient than Pq0. In $I_{d}-I_{q}$, angle $\theta$ can directly be calculated from fundamental voltages, so this technique is frequency-independent due to that many synchronization problems can be tackled easily. Moreover, using controller HIL algorithms, the performance of the HSAHPF is also improved when the sampling time is enhanced; thus, the computational burden of the proposed controller can be handled with existing technology. It is achieved by adjusting the baud rate of Arduino and the number of receiving bits per second. Still, in the case of complex algorithms and mathematical models, the accuracy may be compromised if the stored information contains more bits as the processing speed of Arduino is limited. The waveform of the attained power factor (approximately unity) can be observed in Figure 26.

The findings from our work are significant, but still few limitations of the presented study are, $\mathrm{Pq} 0$ and $I_{d}-I_{q}$ perform better until the supply voltage is in ideal and balanced load condition. If the nature of the attached nonlinear load is unbalanced, the PI controller in $\mathrm{Pq} 0$ and $I_{d}-I_{q}$ do not respond rapidly compared to balanced load conditions. The neural network-based predictive control schemes and the fuzzy logic algorithms provide a fast and accurate dynamic response for a nonlinear system containing uncertain information or unbalanced load. Therefore, optimal control techniques will be more suitable for high switching frequency and real-time testing monitoring conditions. However, implemented prototype model will provide the capability to use Simulink for testing and monitoring the HSAHPF with an external hardware controller using HIL simulations. A real-time application-based hardware system can be implemented using various efficient portable controllers, such as Raspberry pi and FPGA with more computational power.

\section{Conclusion}

In this paper, a hybrid shunt active harmonic power filter (HSAHPF) has been implemented to reduce harmonic pollution and enhance the power quality. Moreover, a controller HIL simulator has been implemented for verification and monitoring a high-power, three-phase power system based on THD bearing nonlinear load. A technoeconomical controller HIL-based HSAHPF with some appropriate control techniques to overcome the power issues has been presented in this paper. The power circuit of HSAHPF is designed and simulated in Simulink, and the control algorithms for reference current generation are implemented in Arduino MEGA for testing of the external controller using HIL simulation, in which the controller processes analog signals for producing gating signal, then for proper switching action, they will be sent back to simulator. The advantages of executed controller HIL over traditional hardware-based HIL systems or laboratory prototypes are summarized in the following points.

(i) The effects of phase delays due to sensors have been presented.

(ii) The effects of phase delays are provided due to measurement circuits. 
(iii) The phase delays caused by reference current generation waveform in laboratory prototypeimplemented controller and system losses are eliminated.

(iv) It is less risky, economical, and portable, with a short development period for testing and validating power systems.

It can be observed from the presented results that the THD for Pq0 implemented in Simulink and Arduino are $3.12 \%$ and $3.44 \%$. On the contrary, THD for $I_{d}-I_{q}$ implemented in Simulink and Arduino are $2.01 \%$ and $2.38 \%$, respectively. Therefore, from the comparative analysis, it can be inferred that $I_{d}-I_{q}$ has more efficient results with a minimum THD, improved stability time, and a power factor nearer to unity. The observed statistics lie within the range of IEEE 519-1992 recommended harmonic standards. Conclusively, the implemented HIL controller operates closely in run-time conditions and provides multiple advantages, such as a reliable testing environment, repeatable and automated test conditions, and firm advancement in technology without actual hardware and power transfer. The realtime application-based hardware systems can be implemented in the future using various efficient portable controllers, that is, Raspberry Pi, FPGA, SDM, and Atmel AVR aided with more computational power and efficient performance.

\section{Appendix}

\section{A. Passive Power Filter Design Components}

The PPF in the HSAHPF contains a single tuned RL circuit. For calculating and designing inductor and resistor regarding the elimination of specific order harmonics, it will use the following equations:

$$
\begin{aligned}
X_{c} & =\frac{v_{x^{2}}}{\overrightarrow{\left|Q_{L}\right|}}, \\
C & =\frac{h^{2}-1}{h}\left(\frac{\overrightarrow{Q_{L} \mid}}{2 \pi f V_{x^{2}}}\right), \\
X_{L} & =\frac{1}{h^{2}} X_{c}, \\
L_{c} & =\frac{1}{(h 2 \pi f)^{2} C}, \\
R & =\frac{\sqrt{X_{C} X_{L}}}{Q},
\end{aligned}
$$

where $V_{x}$ is the phase voltage, $Q_{L}$ is the reactive power of load, $h$ represents the order of harmonics for that PPF needed to be tuned, and $Q$ is the quality factor chosen between the range of 30 to 50 .
Voltage Regulator Design. The voltage is mainly linked with the charging and discharging of the capacitors to give the specific value of DC voltage to VSI to generate an expected waveform for harmonics current. It comprises of PI controller, and its value is determined using the following relation:

$$
V_{\mathrm{DC}}=\frac{2 \sqrt{2} V_{L-L_{\mathrm{rms}}}}{\sqrt{3} m},
$$

where $m=1$; modulation index.

Thus, after mathematical calculation, the value of $\mathrm{V}_{\mathrm{DC}}$ is $622 \mathrm{~V}$.

\section{B. Supplementary Material}

\section{B.1. Reference Current Calculation/Pq0 Block.}

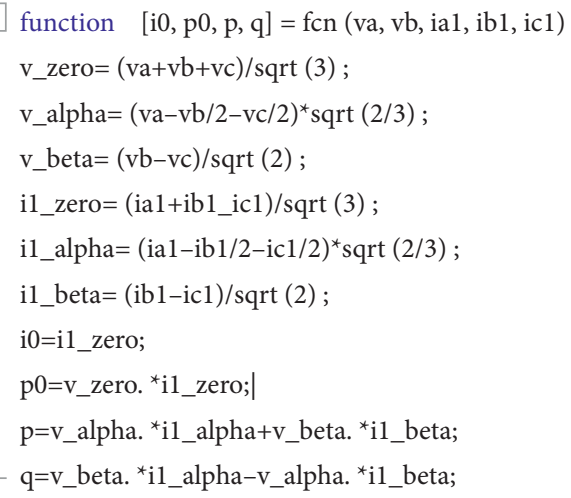

\section{B.2. Reference Current Calculation/Inverse Pq0 Block.}

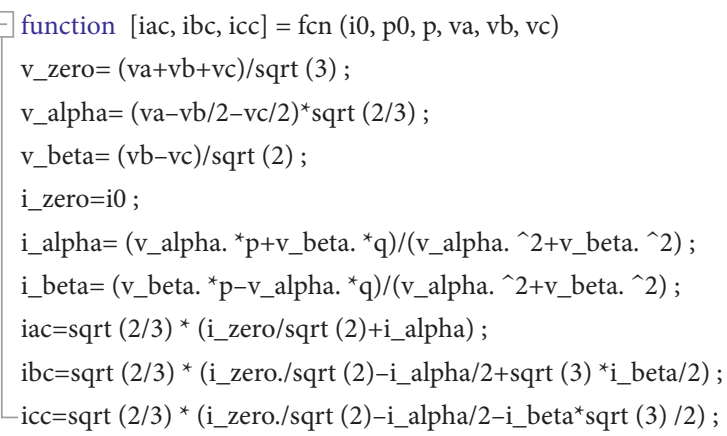

\section{B.3. PLL Mathematical Parameters.}

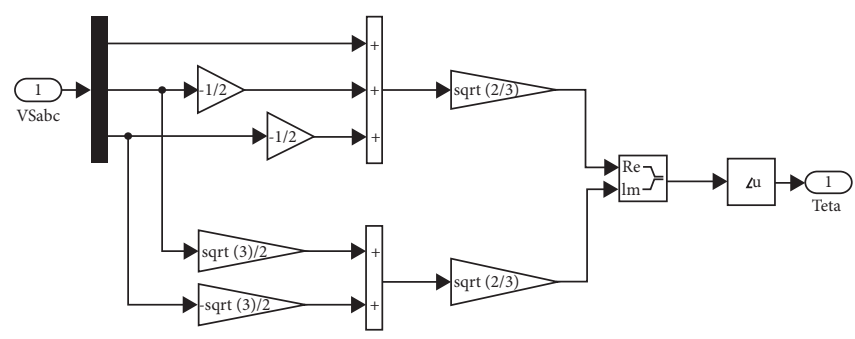


B.4. Reference Current Calculation $/ I_{d}-I_{q}$ Block Calculations.

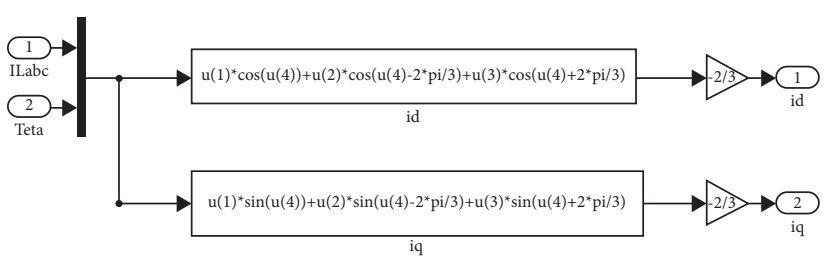

B.5. Reference Current Calculation/Inverse $I_{d}-I_{q}$ Block Calculations.

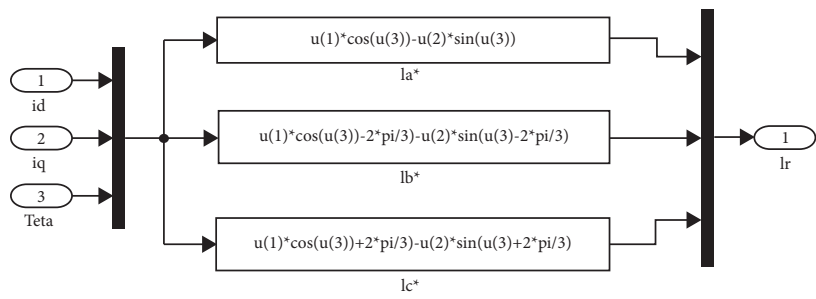

B.6. Hysteresis Block.

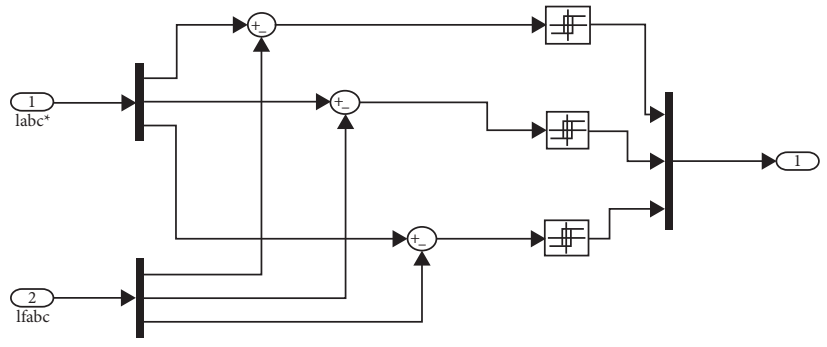

\section{Data Availability}

No data were used to support this study.

\section{Conflicts of Interest}

The authors have no conflicts of interest.

\section{References}

[1] M. El-Habrouk, M. K. Darwish, and P. Mehta, "Active power filters: a review," IEE Proceedings-Electric Power Applications, vol. 147, no. 5, pp. 403-413, 2000.

[2] X. Wang and F. Blaabjerg, "Harmonic stability in power electronic-based power systems: concept, modeling, and analysis," IEEE Transactions on Smart Grid, vol. 10, no. 3, pp. 2858-2870, 2019.

[3] J. Das, "Passive filters-potentialities and limitations," IEEE Transactions on Industry Applications, vol. 40, no. 1, pp. 232-241, 2003.

[4] H. Ambatkar and N. B. Dhande, "REVIEW: active power filtering techniques for power system," International Research Journal of Engineering and Technology (IRJET), vol. 6, no. 3, 2019.

[5] H. Akagi, "Active harmonic filters," Proceedings of the IEEE, vol. 93, no. 12, pp. 2128-2141, 2005.

[6] P. Salmerón and S. P. Litrán, "A control strategy for hybrid power filter to compensate four-wire three-phase system,"
IEEE Transactions on Power Electronics, vol. 25, no. 7, pp. 1923-1931, Article ID 25, 2010.

[7] M. S. A. Dahidah, G. Konstantinou, and V. G. Agelidis, "A review of multilevel selective harmonic elimination PWM: formulations, solving algorithms, implementation and applications," IEEE Transactions on Power Electronics, vol. 30, no. 8, pp. 4091-4106, 2015.

[8] F. M. Albatsh, S. Ahmad, S. Mekhilef, H. Mokhlis, and M. A. Hassan, "DQ model of fuzzy based UPFC to control power flow in transmission network," in Proceedings of the IET International Conference on Power Electronics, Machines and Drives (PEMD 2014), Manchester, UK, April 2014.

[9] S. Samal, P. K. Hota, and P. K. Barik, "Harmonics mitigation by using shunt active power filter under different load condition," in Proceedings of the International Conference on Signal Processing, Communication, Power and Embedded System (SCOPES), Paralakhemundi, India, Octomber 2016.

[10] F. M. Albatsh, S. Mekhilef, S. Ahmad, H. Mokhlis, and M. A. Hassan, "Enhancing power transfer capability through flexible AC transmission system devices: a review," Frontiers of Information Technology \& Electronic Engineering, vol. 16, no. 8 , pp. $658-678,2015$.

[11] E. L. L. Fabricio, S. C. S. Júnior, C. B. Jacobina, and M. B. de Rossiter Correa, "Analysis of main topologies of shunt active power filters applied to four-wire systems," IEEE Transactions on Power Electronics, vol. 33, no. 3, pp. 21002112, 2018.

[12] M. D. Omar Faruque, T. Strasser, G. Lauss et al., "Real-time simulation technologies for power systems design, testing, and analysis," IEEE Power and Energy Technology Systems Journal, vol. 2, no. 2, pp. 63-73, 2015.

[13] R. Balasubramanian, K. Parkavikathirvelu, R. Sankaran, and R. Amirtharajan, "Design, simulation and hardware implementation of shunt hybrid compensator using synchronous rotating reference frame (SRRF)-Based control technique," Electronics, vol. 8, no. 1, pp. 42-61, 2019.

[14] M. Iqbal, M. Jawad, M. H. Jaffery et al., "Neural networks based shunt hybrid active power filter for harmonic elimination," IEEE Access, vol. 9, pp. 69913-69925, 2021.

[15] R. M. Asif, A. U. Rehman, S. U. Rehman et al., "Design and analysis of robust fuzzy logic maximum power point tracking based isolated photovoltaic energy system," Engineering Reports, vol. 9, no. 16, 2020.

[16] C.-I. Chen, C.-K. L. OrcID, Y.-C. Chen, and C.-H. Chen, "Adaptive frequency-based reference compensation current control strategy of shunt active power filter for unbalanced non-linear loads," Energies, vol. 12, no. 6, pp. 3080-3093, 2019.

[17] A. Javadi, M. Abarzadeh, L.-A. Grégoire, and K. Al-Haddad, "Real-time HIL implementation of a single-phase distribution level THSeAF based on D-NPC converter using proportionalresonant controller for power quality platform," IEEE Access, vol. 7, pp. 110372-110386, 2019.

[18] A. K. Mishra, S. R. Das, P. K. Ray, R. K. Mallick, A. Mohanty, and D. K. Mishra, "PSO-GWO optimized fractional order PID based hybrid shunt active power filter for power quality improvements," IEEE Access, vol. 8, pp. 74497-74512, 2020.

[19] H. Li, A. M. Gole, and C. N. M. Ho, "Controller implementation and performance evaluation of a high power threephase Active power filter using controller hardware-in-theloop simulation," in Proceedings of the 2018 IEEE Electrical Power and Energy Conference (EPEC), Toronto, ON, Canada, Octomber 2018. 
[20] L. Herman, A. Božiček, B. Blažič, and I. Papič, "Real-time simulations of a parallel hybrid active filter with hardware-inthe-loop," in Proceedings of the 2014 16th International Conference on Harmonics and Quality of Power (ICHQP), Bucharest, Romania, May 2014.

[21] P. Dey, S. Ahmad, S. Mekhilef, and F. Albatsh, "Real time implementation of 3-phase 4-wire shunt hybrid active power filter based on PI controller," Journal of Testing and Evaluation, vol. 45, no. 2, pp. 648-663, 2017.

[22] A. Tan, K. Ç. Bayındır, M. U. Cuma, and M. Tümay, "Multiple harmonic elimination-based feedback controller for shunt hybrid active power filter," IET Power Electronics, vol. 10, no. 8, pp. 945-956, 2017.

[23] A. A. Imam, R. S. Kumar, and Y. A. Al-Turki, "Modeling and simulation of a PI controlled shunt active power filter for power quality enhancement based on P-Q theory," Electronics, vol. 9, no. 4, pp. 1-17, 2020.

[24] A. Kumar and P. Mikkili, "FLC based shunt active filter ( $p-q$ and $I_{d}-I_{q}$ ) control Strategies for mitigation of harmonics with different fuzzy MFs using MATLAB and real-time digital simulator," International Journal of Electrical Power \& Energy Systems, vol. 47, pp. 313-336, 2013.

[25] M. S. Almutairi and S. Hadjiloucas, "Harmonics mitigation based on the minimization of non-linearity current in a power system," Design, vol. 3, no. 2, pp. 1-12, 2019.

[26] H. Akagi and E. H. Watanabe, Instantaneous Power Theory and Applications to Power Conditioning, Wiley \& Sons, Hoboken, NJ, USA, 2017.

[27] M. Jawad and M. Iqbal, Neural Networks Based Shunt Hybrid Active Power Filter Design for Harmonics Elimination, Mendeley, London, UK.

[28] D. Bellan, "Clarke transformation solution of asymmetrical," Energies, vol. 13, no. 19, 2020.

[29] P. Santiprapan, K.-L. Areerak, and K.-N. Areerak, "Mathematical model and control strategy on DQ frame for shunt active power filters," International Journal of Electrical, Computer, Energetic, Electronic and Communication Engineering, vol. 5, pp. 353-361, 2011.

[30] B. Lundstrom and M. V. Salapaka, "Optimal power hardwarein-the-loop interfacing: applying modern control for design and verification of high-accuracy interfaces," IEEE Transactions on Industrial Electronics, vol. 68, no. 11, pp. 1038810399, 2021. 